Net, S., Sempéré, R., Delmont, A., Paluselli, A., Ouddane. B., 2015. Occurrence, fate and behavior and ecotoxicological state of phthalates in different environmental matrices. Environ.

Sci. Technol. 49 (7), 4019-4035. DOI: 10.1021/es505233b.

\title{
Occurrence, Fate, Behavior and Ecotoxicological State of Phthalates in Different Environmental Matrices
}

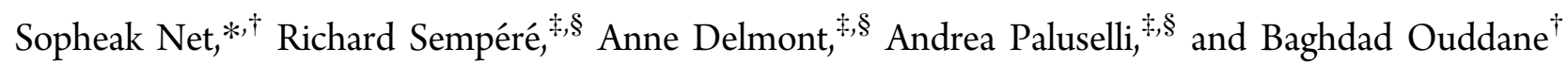 \\ ${ }^{\dagger}$ Lille University, LAboratoire de Spectrochimie Infrarouge et Raman (LASIR)-UMR CNRS 8516, Equipe Physico-chimie de \\ l'Environnement, Cité Scientifique 59655 Villeneuve d'Ascq, France \\ ${ }^{\ddagger}$ Aix-Marseille University, Mediterranean Institute of Oceanography (MIO), Marseille, CEDEX 9, 13288, France \\ ${ }^{\S}$ Université de Toulon, Toulon, CNRS/IRD, 83957, France
}

Supporting Information

ABSTRACT: Because of their large and widespread application, phthalates or phthalic acid esters (PAEs) are ubiquitous in all the environmental compartements. They have been widely detected throughout the worldwide environment. Indoor air where people spend $65-90 \%$ of their time is also highly contaminated by various PAEs released from plastics, consumer products as well as ambient suspended particulate matter. Because of their widespread application, PAEs are the most common chemicals that humans are in contact with daily. Based on various exposure mechanisms, including the ingestion of food, drinking water, dust/soil, air inhalation and dermal exposure the daily intake of PAEs may reach values as high as $70 \mu \mathrm{g} / \mathrm{kg} /$ day. PAEs are involved in endocrine disrupting effects, namely, upon reproductive physiology in different species of fish and mammals. They also present a variety of additional toxic effects for many other species including terrestrial and aquatic fauna and flora. Therefore, their presence in the environment has attracted considerable attention due to their potential impacts on ecosystem functioning and on public health. This paper is a synthesis of the extensive literature data on behavior, transport, fate and ecotoxicological state of PAEs in environmental matrices: air, water, sediment, sludge, wastewater, soil, and biota. First, the origins and physicochemical properties of PAEs that control the behavior, transport and fate in the environment are reviewed. Second, the compilation of data on transport and fate, adverse environmental and human health effects, legislation, restrictions, and ecotoxicological state of the environment based on PAEs is presented.

\section{INTRODUCTION}

PAEs are widely used in the manufacture and processing of plastic products as plasticizers. Production of PAEs began in the 1920s and has intensified since 1950, when these compounds were used to impart flexibility to polyvinyl chloride (PVC) resins. ${ }^{1}$ To date, plasticizers are used in a very broad range of industrial applications. ${ }^{2,3}$ Not chemically but only physically bound to the polymeric matrix, PAEs can easily be released into the environment directly and/or indirectly, during manufacture, use, and disposal. ${ }^{4}$ To date, PAEs are ubiquitous in the environment, including atmospheric aerosols, ${ }^{5,6}$ sludge from sewage and wastewater treatment, ${ }^{7}$ river and marine waters/ sediments, ${ }^{5,8}$ drinking water, ${ }^{9}$ biota, and air. ${ }^{10,12}$

Some PAEs are endocrine disrupting chemicals, and their environmental behavior has attracted considerable attention due to their potential impact on ecosystem functioning and on public health. Consequently, six of them have been placed on the priority pollutant list of the United States Environmental Protection Agency (U.S. EPA), the European Union (EU), and on the list of priority pollutants in Chinese waters, ${ }^{13,14}$ and the concentrations of PAEs have been regulated for water consumption. The use of PAEs is now subject to stricter control and some have been prohibited or their reduction in numerous products has been recommended. A list of acronyms and abbreviations used in this review is provided in Table $1 S$ in Supporting Information (SI).

I. Phthalates. I.1. Origin. Although di- $n$-butyl phthalate (DnBP) and di(2-ethylhexyl) phthalate (DEHP) can be synthesized by red algae ${ }^{15}$ their natural origins are negligible compared with PAEs produced by human activities. Industrial use of PAEs that began in the 1930s is very broad on the worldwide scale. ${ }^{16}$ To date, worldwide anual production of plastics has reached a level of 150 million tons, and 6-8 million tons of PAEs are consumed each year. European consumption of PAEs accounts for approximately 1 million tons. ${ }^{17,18}$ The production of PAEs increased from 1.8 million tons in $1975^{19}$ to more than 8 million tons in 2011. ${ }^{18}$ PAEs are used in a very broad range of applications, 2,3 and their content can be up to $10-60 \%$ by weight. ${ }^{20,21}$ PAEs are present in many materials or

Received: October 29, 2014

Revised: January 15, 2015

Accepted: March 2, 2015 


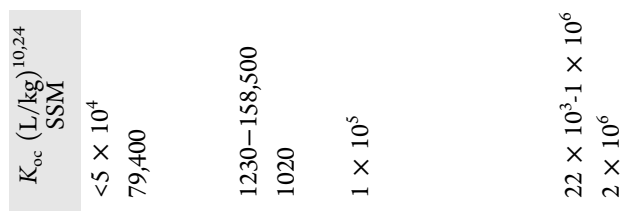

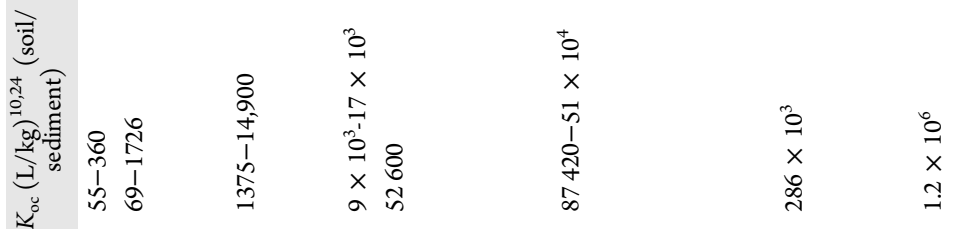

ले

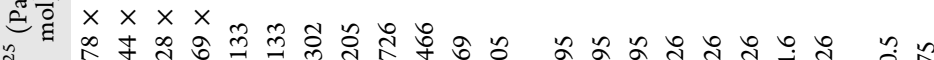

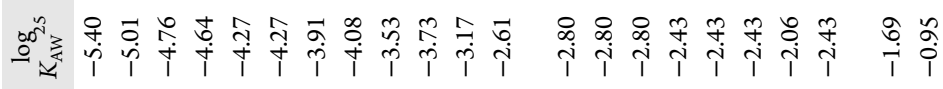

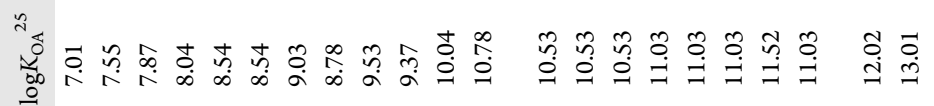

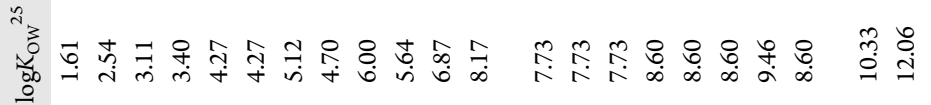
-

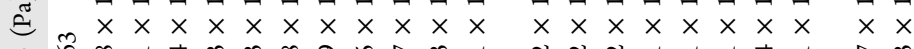

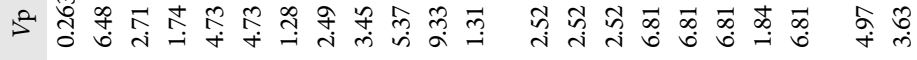

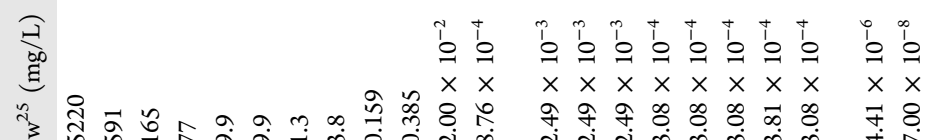

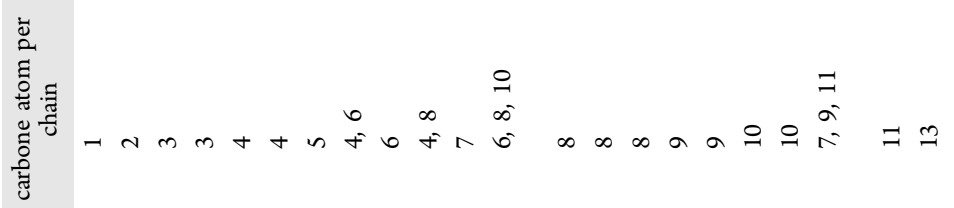

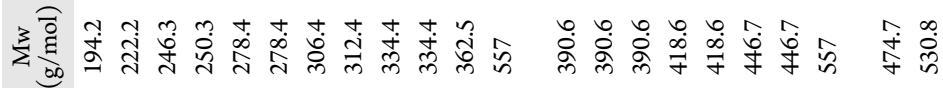

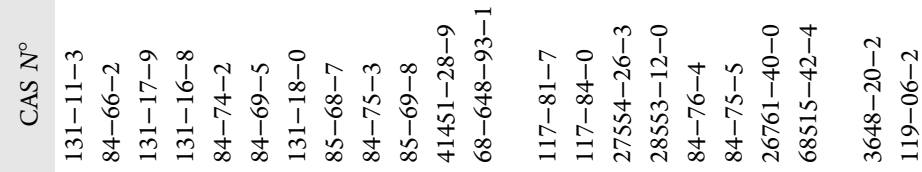

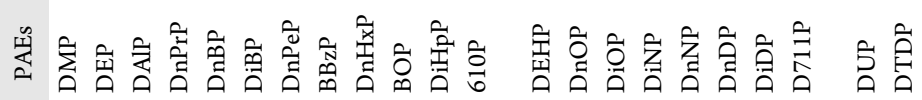

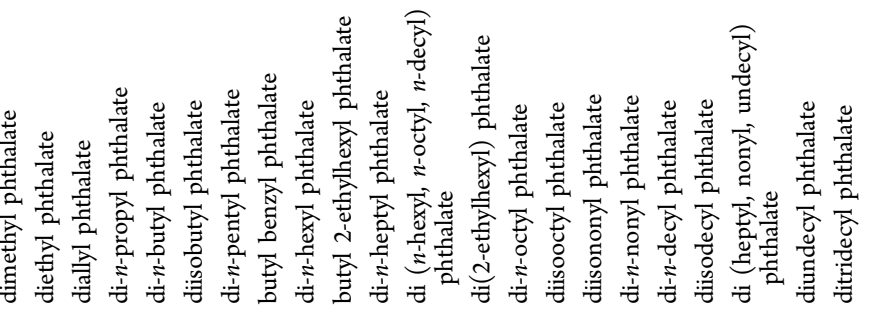


products including PVC products, building materials (paint, adhesive, wall covering), personal-care products (perfume, eye shodaw, moisturizer, mail polish, deodorizer, liquid soap, and hair spray), medical devices, detergents and surfactants, packaging, children's toys, printing inks and coatings, pharmaceuticals and food products, textiles, household applications such as shower curtains, floor tiles, food containers and wrappers, cleaning materials.

Low molecular weight PAEs such as dimethyl phthalate (DMP), diethyl phthalate (DEP), and DnBP are components of industrial solvents, solvents in perfumes, adhesives, waxes, inks, pharmaceutical products, insecticide materials, and cosmetics. $^{22}$ DMP and DEP allow perfume fragrances to evaporate more slowly, lengthening the duration of the scent, and a small amount of DnBP gives nail polish a chip-resistant property. PAEs with longer alkyl chains are used as plasticizers in the polymer industry to improve flexibility, workability, and general handling properties, and $80 \%$ of PAEs are used for this purpose. $^{23}$ The dispersion of PAEs in the environment can occur at all stages of their use, from their synthesis to their transformation or degradation.

I.2. Physicochemical Properties. A few key physicochemical properties including water solubility $\left(S_{\mathrm{W}}\right)$, vapor pressure $(\mathrm{Vp})$, Henry's constant $(H)$, air-water partitioning $\left(K_{\mathrm{AW}}\right)$, octanol-air partition $\left(K_{\mathrm{OA}}\right)$, and octanol-water partitioning $\left(K_{\mathrm{OW}}\right)$, organic carbon partitioning $\left(K_{\mathrm{OC}}\right)$ control both the behavior, transport and fate in the environment and also the exchanges between the different reservoirs such as atmosphere, lithosphere, hydrosphere, and biosphere. ${ }^{10,24,25} S_{\mathrm{W}}$ controls the distribution between water, soil/sediment, and atmosphere. Table 1 shows that $S_{\mathrm{W}}$ of PAEs are low and decrease with the increase in the carbon chain length. $K_{\mathrm{OW}}$ translates the affinity of an organic compound with the lipid molecules in living organisms. $K_{\mathrm{OW}}$ has been used to predict the tendency of a contaminant to concentrate in aquatic organisms. ${ }^{26} \log K_{\mathrm{OW}}$ increases with increasing alkyl chain length, indicating greater bioconcentration (Table 1). Vp declines more than 7 orders of magnitude with increasing alkyl chain length. Moreover, $H$ indicates the tendency of a substance to escape from water into air. $H$ can be calculated from $\mathrm{Vp}$ and $S_{\mathrm{W}}$. Compounds with $H$ values $\sim 1.01 \times$ $10^{-2} \mathrm{~Pa} \cdot \mathrm{m}^{3} / \mathrm{mol}$ are generally considered to have negligible volatility. For higher alkyl chains ranging from 4 to 13 carbon atoms, $H$ values range from 0.133 to $275 \mathrm{~Pa} \cdot \mathrm{m}^{3} / \mathrm{mol}$ which indicates that transfer from the aqueous phase to the gas phase is important (Table 1). $K_{\mathrm{OC}}$ of PAEs range from 55 to 360 for DMP to $1.2 \times 10^{6}$ for ditridecyl phthalate (DTDP) in soil/ sediment and from 1020 for diisobutyl phthalate (DiBP) to $2 \times$ $10^{6}$ for di-n-octyl phthalate (DnOP) in suspended solids matter (SSM) (Table 1). $K_{\mathrm{AW}}$ and $K_{\mathrm{OA}}$ partition coefficients are among the key factors controlling the distribution of PAEs in different matrices in the environment. $\log K_{\mathrm{AW}}$ and $\log K_{\mathrm{OA}}$ increase with the increasing alkyl chain length. High values of $\log K_{\mathrm{OA}}$ suggest that PAEs present in the atmosphere will be appreciably sorbed to aerosol particles and to soil and vegetation, whereas high values of $\log K_{\mathrm{AW}}$ suggest that PAEs potentially evaporate more rapidly from water. However, rapid evaporation from water could be mitigated by sorption to SSM in the water. ${ }^{25}$ The lower molecular weight PAEs are quite volatile and have very low $\log K_{\mathrm{AW}}$ values, so they will volatilize rapidly from the pure state but only very slowly from aqueous solution. ${ }^{25}$

II. Environmental Transport, Fate, Behavior. PAEs can be removed from environmental matrices by some processes that include microbiological transformation and degradation, volatilization, photo-oxidation, photolysis, sorption and biological uptake. ${ }^{10,24,27,28}$ Field and laboratory studies have shown that aerobic or anaerobic microorganisms from various habitats (water, sediment, soil) are able to degrade PAEs. However, the half-lives of PAEs depend strongly on the condition of each habitat such as oxidant, microbial density, and sunlight irradiation.

Special attention should be focused on quality control/ assurance (QC/QA) when quantifying PAEs concentation in environmental matrices. Literature data showed that one of the main problems for PAEs analysis is the risk of contamination, as PAEs are ubiquitous and could be present in water, organic solvents, air, glassware and in the plastic material used for the analysis. The primary issue for the quantification of PAEs is not the trace analysis itself but the risk of contaminating the environmental samples during the analytical procedure, which can often lead to false positive or overestimated result. Thus, special attention should be focused on the quality controle and quality assurance when determined PAEs concentation. QC should be routinely implemented to minimize the risk of sample contamination. The blank should be free from any targeted PAEs to ensure that no significant contamination occurs during the whole procedure and ensure thus the reliable results. If PAEs are present at low concentrations, which account for less than a few \% of those in the targeted sample, it is not necessary to subtract them from the sample measurement. However, if they are present at significant levels, they must be eliminated or subtracted from the sample measurement. $^{29}$

II.1. Air. PAEs are ubiquitous in the atmosphere, including air indoors where people spend $65-90 \%$ of their time. ${ }^{30,31}$ Indoor environments increase the lifetime of pollutants adsorbed to particles and dust by minimizing or eliminating the natural decomposition processes catalyzed by sunlight and rain. ${ }^{32}$ Indeed, direct photolysis and photodegradation are major reaction pathways of PAEs responsible for PAE decay in the atmosphere. DEP and butyl cyclohexane phthalate (BCP) react photochemically with $\mathrm{OH}^{\bullet}$ with an estimated half-life of 22.2 and $23 \mathrm{~h}$, respectively. ${ }^{33}$ For DMP and DEHP, photolysis is important in the atmosphere where the indirect process of $\mathrm{OH}^{\bullet}$ attack predominates. The half-lifes of individual PAEs were estimated to be several days (see Supporting Information Table $4 S)^{3434}$. Half-life of photo-oxidation of PAEs increases with the increasing alkyl chain length and $\mathrm{OH}^{\bullet}$ concentration. DnBP and DEHP have been used as softeners in water-based synthetic paintings, ${ }^{35}$ so these compounds can be released into the atmosphere from painted surfaces ${ }^{36}$ or photodegraded on mural painting surfaces under UV light irradiation in a dozen of hours (Supporting Information Table $4 \mathrm{~S}) .{ }^{11}$ On a mural painting, $68 \%$ of the total PAEs were degraded by irradiation only for a time period of $8 \mathrm{~h}$.

PAEs can also be removed from the atmosphere by wet and dry deposition. PAEs with short carbon chains $(<6)$ are present mainly in the gas phase, while PAEs with longer chains are mainly adsorbed on the particles. ${ }^{12,37}$ Wet deposition is an important source of removal of short alkyl chains while dry deposition is an important source of removal of PAEs with long alkyl chains. Depositional fluxes of $\Sigma_{16}$ PAEs were estimated from 3.41 to $190 \mu \mathrm{g} \cdot \mathrm{m}^{2}$ /day for strong anthropogenic activity zones. This deposition process is initiated preliminarily by the association of PAEs with atmospheric particles. Among the 16 PAEs, DiBP, DnBP, and DEHP were the dominant ones. ${ }^{38}$ 
Atmospheric transport and deposition of PAEs can also be a significant process for their occurrence in soil and in the remote Atlantic and Arctic Oceans. The air-sea vapor exchange is an important process that intervenes in the mass balance of PAEs in the North Sea. ${ }^{36,39}$ The concentrations of PAEs were $<$ n.d. to $3.4 \mathrm{ng} / \mathrm{m}^{3}$ in the atmosphere and < n.d. to $6.6 \mathrm{ng} / \mathrm{L}$ in the water phase. The average of the air-sea exchange fluxes was estimated at $-338 \mathrm{ng} / \mathrm{m}^{2} /$ day for DnBP and $-13 \mathrm{ng} / \mathrm{m}^{2} /$ day for $\mathrm{BBzP}$, suggesting a net deposition. However, the air-sea exchange fluxes of DEHP ranged from -95 to $686 \mathrm{ng} / \mathrm{m}^{2} /$ day with average of $53 \mathrm{ng} / \mathrm{m}^{2} /$ day, indicating that DEHP can be both deposited and volatilized from the surface water but volatilization is dominant. Volatilization and deposition process of PAEs in air-sea interface depend on the $H$. PAEs with low $H$ values such as $\mathrm{DnBP}$ and $\mathrm{BBzP}$ were preferentialy deposited on sea surface, whereas DEHP with high $H$ was dominated by volatilization. Air-sea exchanges of PAEs have also been estimated for the Norwegian, the Greenland, and the Arctic seas $^{5}$ with total concentrations of $30-5030 \mathrm{pg} / \mathrm{L}$ and $1110-$ $3090 \mathrm{pg} / \mathrm{m}^{3}$ in the aqueous dissolved phase and the atmospheric gas phase, respectively. For DEHP, deposition dominated the air-sea gas exchange, while volatilization from seawater took place in the near-coast environment. The estimated net gas deposition of DEHP was 5, 30, and 190 tons per year for the Norwegian, the Greenland and the Arctic Seas, respectively, ${ }^{5}$ suggesting that atmospheric transport and deposition of PAEs is a significant process for their occurrence in the remote Atlantic and Arctic Oceans.

II.2. Water. PAEs can be accumulated in the hydrosphere via numerous processes, namely, atmospheric deposition, leaching, and drainage. ${ }^{5,40-42}$ Hydrolysis of PAEs is negligible at neutral $\mathrm{pH}$ with aqueous hydrolysis half-lives in order of several years and up to more than 100 years for DnOP, DiOP and DEHP (see Supporting Information Table 4S). ${ }^{43}$ UVB can penetrate surface water and induce photolysis of PAEs either directly by direct absorption of radiation or indirectly by the oxidation reactions of reactive chemical species such as $\mathrm{OH}^{\bullet}, \mathrm{CO}_{3}{ }^{-\bullet},{ }^{1} \mathrm{O}_{2}$, $\mathrm{O}_{2}^{-\bullet}$, and chromophoric dissolved organic matter (CDOM) triplet states produced in surface waters by sunlight illumination of photoactive molecules (photosensitizers) such as nitrate, nitrite, and CDOM. ${ }^{44,45}$ Under these conditions, aqueous half-lives of PAEs decrease considerably and ranging between 2.4 and 12 years and $0.12-1.5$ years for DEP and DEHP, respectively. ${ }^{46}$ Under light irradiation, PAEs react with photogenerated $\mathrm{OH}^{\bullet}$ to form 4-hydroxy phthalate esters that present potential toxicity. ${ }^{27}$

Biodegradation can be the most important process for the removal of PAEs from water. Indeed, PAEs can be accumulated and degraded rapidly by microorganism under both aerobic and anaerobic conditions. In surface waters (seawater or freshwater) under aerobic conditions excluding low temperatures $\left(<5{ }^{\circ} \mathrm{C}\right)$ and poor nutritional conditions, the half-lives of primary degradation vary from less than 1 day to 2 weeks, and the halflives for complete mineralization are approximately 10 times longer. ${ }^{10}$ However, Cousins and $\mathrm{Palm}^{47}$ have reported the water half-life of DEHP and DiNP at 360 and $900 \mathrm{~h}$, respectively (Supporting Information Table 4S). The biodegradation of PAEs varies depending on the density and type of species. DEP was detected in aquatic organisms with a modest level, ${ }^{48,49}$ and it is unlikely to biomagnify up the food chain because it is degraded by organisms. ${ }^{50}$ The order of biodegradation of PAEs was algae <cnidarians <molluscs $<$ crustaceans $<$ fish. ${ }^{51}$ The half-life of DEP in fish tissue is $1-$
2 days. ${ }^{52,53}$ Although DEHP can be volatilized from seawater in the near-coast environment, global tendencies suggest that deposition dominates the air-sea exchange of PAEs.,39

II.3. Sediment. Few studies have focused on the biodegradability of PAEs in river and marine sediment. The kinetics of anaerobic degradation of PAEs in river sediment depends on various factors including $\mathrm{pH}$, temperature, surfactants, pollutants, or microbial inhibitors. Microbial action is thought to be the principal mechanism for PAEs degradation in both aquatic and terrestrial systems (e.g., sewage, soils, sediments, water) ${ }^{10,24}$ In mangrove sediments, under aerobic condition, the degradation half-lives of DnBP and DEHP were estimated to be only fews days (SI Table 4S). Similar half-lives of DEP, DnBP, and DEHP were found for river sediment under anaerobic conditions $\left(30{ }^{\circ} \mathrm{C} \text { with } \mathrm{pH} 7\right)^{56}$ (Supporting Information Table $4 S$ ). For river sediment under anaerobic conditions, DnBP, DPhP, and BBzP might be degraded rapidly whereas DEP and DEHP degradation rates were very low. 54,55 Primary biodegradation rates in sediments were estimated at 3-4 weeks and 3 months, respectively, for DnBP and DEHP. ${ }^{57,58}$ Sediment half-life of DEHP and DiNP were estimated at less than 1 year $^{47}$ (Supporting Information Table $4 S$ ). Otton et al. ${ }^{59}$ measured the biodegradation kinetics of eight monoalkyl phthalate esters (MPEs) in marine and freshwater sediments collected from three locations in the Greater Vancouver area. The studied MPEs were degraded in both marine and freshwater sediments at $22{ }^{\circ} \mathrm{C}$ with half-lives ranging between 16 and $39 \mathrm{~h}$. In marine sediments, half-lives of these eight MPEs were found in the ranges of $18 \pm 4-35 \pm 10$ $\mathrm{h}$, which is similar to the range of half-lives found in freshwater sediment $(16 \pm 2-39 \pm 6 \mathrm{~h}) .{ }^{59}$ These results suggest that the half-life of PAEs increased strongly (ca. 8-fold) with temperatures in the range of $5-22{ }^{\circ} \mathrm{C}$ and did not depend on alkyl chain length.

II.4. Soil. Atmospheric deposition and sewage sludge used as soil amendment are the important sources of PAEs in soil, especially in agricultural areas. The most abundant PAEs in soil are DiBP, DnBP and DEHP, which represent $74.2-99.8 \%$ of $\sum_{16}$ PAEs. $^{41}$ In soil, the half-lives of PAEs vary from 1 to 75 days, much lower than the half-life found for polychlorobiphenyls $\left(7-25\right.$ years) under the same conditions. ${ }^{17}$ DEP was not expected to persist in the environment with a degradation half-life in soil of approximately 0.75 days at $20{ }^{\circ} \mathrm{C}$, whereas only $10 \%$ of DEHP was removed from the same soil after 70 days incubation. ${ }^{60}$ However, more recently, Cousins and Palm $^{47}$ have reported the soil half-life of DEHP and DiNP at 30 and 75 days, respectively.

Depending on meteorological conditions, PAEs in soil can also contribute to water or atmospheric pollution by evaporation, leaching, deposition and drainage, ${ }^{40-42}$ consequently modifying their concentration and fate. Abiotic degradation experiments of DnBP and DEHP indicated that only $0.60-2.91 \%$ were degraded during 30 days which is much slower than their biodegradation, ${ }^{40}$ depending on the type of soil. Half-lives of DnBP and DEHP were estimated at 7.8 \pm 0.1 and $26.3 \pm 0.7$ days in black soil versus $8.3 \pm 0.2$ and $30.8 \pm$ 0.7 days in fluvo-aquic soil likely due to the higher density of microorganisms in the former case. ${ }^{40}$

III. Impact on Biosphere and Regulation. The toxicity of PAEs remains under debate because the debate is characterized by tension between the commercial importance of PAEs and their impact on human health and on the environment. However, a large variety of field and laboratory studies reveals 
high exposure and evident toxicity of PAEs affecting human health and other biospheres.

III.1. Human Exposure and Health Impact. For humans, the potential pathways for exposure to PAEs are inhalation, contaminated foodstuffs, drinking water or dermal contact with cosmetics containing PAEs. ${ }^{22,61,62}$ Thus, the study of PAEs in air, foodstuffs, drink and other products in human life has been paid more attention. ${ }^{63-65}$ Concentration levels of some individual PAE in milk, drink and food are presented in Table $2 S$ in Supporting Information. The concentrations of individual PAE were detected from not detected level to fews thousands $\mathrm{ng} / \mathrm{g} \mathrm{dw}$ and can be up to $24 \mu \mathrm{g} / \mathrm{g} \mathrm{dw}$ in foods (DEHP in olive oil) and $215 \mu \mathrm{g} / \mathrm{L}$ in milk (Supporting Information Table $2 \mathrm{~S}$ ). The low molecular weight PAEs (DMP, DEP) were found at much lower levels compared to the high molecular weight PAEs and the highest was detected for DEHP (Supporting Information Table 2S). Total PAEs were detected in the range $0.133-3.804 \mu \mathrm{g} / \mathrm{L}$ in drinking water $^{64,66}$ whereas $\sum_{17}$ PAEs ranged from 0.29 to $23.77 \mu \mathrm{g} / \mathrm{m}^{3}$ in indoor air and within $123-9504 \mu \mathrm{g} / \mathrm{g}$ in the dust phase. ${ }^{12}$ High levels of PAEs were detected in indoor air where people spent $65-90 \%$ of their time. ${ }^{30,31,67}$ The daily intake of six PAEs through air inhalation in indoor air has been estimated for infants, toddlers, children, teenagers and adults. ${ }^{65}$ The total exposure doses were within the median daily intake of $155.850-664.332 \mathrm{ng} / \mathrm{kg} /$ day for $\sum_{6} \mathrm{PAEs}$, and the highest level was detected in infants. The daily exposure to indoor PAEs in indoor air and dust was estimated to range from $2.6 \mu \mathrm{g} / \mathrm{kg} /$ day (for adults) to $7.4 \mu \mathrm{g} /$ $\mathrm{kg} /$ day (for toddlers). ${ }^{12}$

Overall, from various exposure pathways based on ingestion of food, drinking water, dust/soil, air inhalation, oral and dermal exposure pathways, daily intake of DMP, DEP, DnBP, $\mathrm{DiBP}, \mathrm{BBzP}$, and DEHP has been estimated in the range of $0.08-69.58 \mu \mathrm{g} / \mathrm{kg} /$ day. $^{64,68}$ Food as the major contributor represents more than $67 \%$ of human exposure. ${ }^{64}$ Consequently, PAEs and their metabolites have been detected in the human body (i.e., breast milk, blood, urine). ${ }^{69,70}$ In urine, metabolites of DnBP and DEHP were the main PAEs metabolites (PAEMs) detected. ${ }^{69}$ Urinary PAEMs concentrations did not depend on sexes but they depend significantly on age. ${ }^{69}$ The most frequently detected PAEs were reported to be DnBP and DEHP, found at highest levels in venous blood followed by breast milk, umbilical cord blood and urine; this order depends on metabolic factors. ${ }^{70}$ When ingested through contaminated food, PAEs are converted by intestinal lipases to MPE, suggesting that DEHP was converted to mono-2-ethylhexyl phthalate (MEHP), while DnBP and $\mathrm{BBzP}$ were converted to the toxic metabolite monobenzyl phthalate $(\mathrm{MBzP}){ }^{71,72}$ High levels of four urinary phthalate metabolites have been reported. ${ }^{73}$ Blood, serum and urine are the general choice of biological matrixes to assess the level of PAEs and their metabolites exposure in human. However, hair is an alternative biological specimen. In urine, MnBP was found to be the highest, followed by the metabolites MEP, MEHP and MiNP with, respectively, $71.42 \pm 90.19,68.32 \pm 43.74,15.37 \pm 20.09$, and $1.47 \pm 4.47 \mathrm{ng} / \mathrm{mL}$. In epidemiological studies, DEHP has been associated with the development of wheezing and allergic airway diseases. ${ }^{74,75}$ Some PAEs are known to be toxic to the developing male reproductive system, and low-molecularweight PAEs have been found to cause irritation of eyes, nose and throat. ${ }^{76}$ Some PAEs (DnBP, DEHP) and their metabolite (MBP) can cause serious to humain health. Given the high contributor of food $(>67 \%)$ on human exposure, stricter controls should be adopted for food to minimize the effect of PAEs on human health.

However, despite the cited adverse effects, DEHP could be beneficial for the patients with glioblastoma multiforme. Exposure of glioblastoma cells to DEHP revealed a significant inhibition of cell migration and invasion and led to a significant reduction in cell proliferation. ${ }^{77}$

The main concerns related to exposure to PAEs in humans are the effects on reproduction, including fertility problems (effect of endocrine disruption), the development of newborns and carcinogenic character. ${ }^{34}$ Howdeshell et al. ${ }^{78}$ have reported that when PAEs were mixed with other antiandrogenic compounds, the effect cumulative on male reproductive tract development when administered during sexual differentiation in utero, potentially affecting human reproductive development were observed.

III.2. Potential Environmental Risk. Numerous studies have focused on the ecotoxicology of PAEs in biota including aquatic organisms and rodents. The latter is useful to estimate the toxicity to humans. Compilation data of DnBP and DEHP showed that aquatic organisms can accumulate high levels of PAEs. ${ }^{10}$ More recently, Vethak et al. ${ }^{79}$ reported contamination of DEP and DEHP in freshwater species such as the bream at $1900-3120 \mu \mathrm{g} / \mathrm{kg} \mathrm{dw}$ of DEHP and $720-800 \mu \mathrm{g} / \mathrm{kg} \mathrm{dw}$ of DEP and for such marine species as the flounder, at $40-70 \mu \mathrm{g} /$ $\mathrm{kg} \mathrm{dw}$ of DEHP and $100-200 \mu \mathrm{g} / \mathrm{kg} \mathrm{dw}$ of DEP.

PAEs are involved in endocrine disrupting effects, namely, upon reproductive physiology in different species of fish and mammals. ${ }^{80}$ They are also toxic for many other species: for DEP, LC50/EC50 values ranged from $3 \mathrm{mg} / \mathrm{L}$ (marine alga) to $132 \mathrm{mg} / \mathrm{L}$ (protozoan), with the lowest NOECs for algae, invertebrates, and fish in the range of $1.7-4 \mathrm{mg} / \mathrm{L} .{ }^{24}$ PAEs acquire unequivocal estrogenic activity under light irradiation that leads to the formation of 4-hydroxy PAEs. ${ }^{27}$ A recent study reported that exposure to DEHP from hatching to adulthood accelerated the start of spawning and decreased the egg production of exposed marine madaka females whereas exposure to both DEHP and MEHP resulted in a reduction of the fertilization rate of oocytes spawned by untreated females paired with treated males. ${ }^{81}$ DEHP induced histological changes in the testes and ovaries: the testes displayed a reduced number of spermatozoa, and the ovaries displayed an increased number of atretic follicles. The toxic effects of DEHP may be induced by both DEHP itself and DEHP metabolites, including MEHP. ${ }^{81}$ Using a $72 \mathrm{~h}$ zebrafish embryo toxicity test, LC50 values of BBzP, DnBP and a mixture of six PAEs were 0.72, 0.63, and $0.50 \mathrm{mg} / \mathrm{L}$, respectively. ${ }^{82} \mathrm{DEHP}$, DiDP, DiNP, and DnOP did not cause more than $50 \%$ exposed embryo mortality even at high concentrations. The symptoms caused by PAEs in aquatic organisms were death, tail curvature, necrosis, cardio edema, and no touch response. This work highlighted the developmental toxicity of $\mathrm{BBzP}$ and $\mathrm{DnBP}$ and the estrogenic endocrine disrupting activity of $\mathrm{BBzP}, \mathrm{DnBP}$, DEHP, and DiNP on intact organisms. ${ }^{82,83}$ The effects of PAEs on wildlife are multiples. The estrogenic effect is one of the important biological impacts of PAEs on wildlife. ${ }^{80,83}$ They appear to act by interfering with the functioning of various hormone systems. ${ }^{83}$ DMP, BBzP, DnBP, and DEHP have been shown to affect reproduction in annelids (both aquatic and terrestrial), molluscs, crustaceans, insects, fish and amphibians, to impair development in crustaceans and amphibians and to induce genetic aberrations. ${ }^{83}$ 
Table 2. Regulations and Guidelines Applicable to Some PAEs Are Listed in Priority List ${ }^{a}$

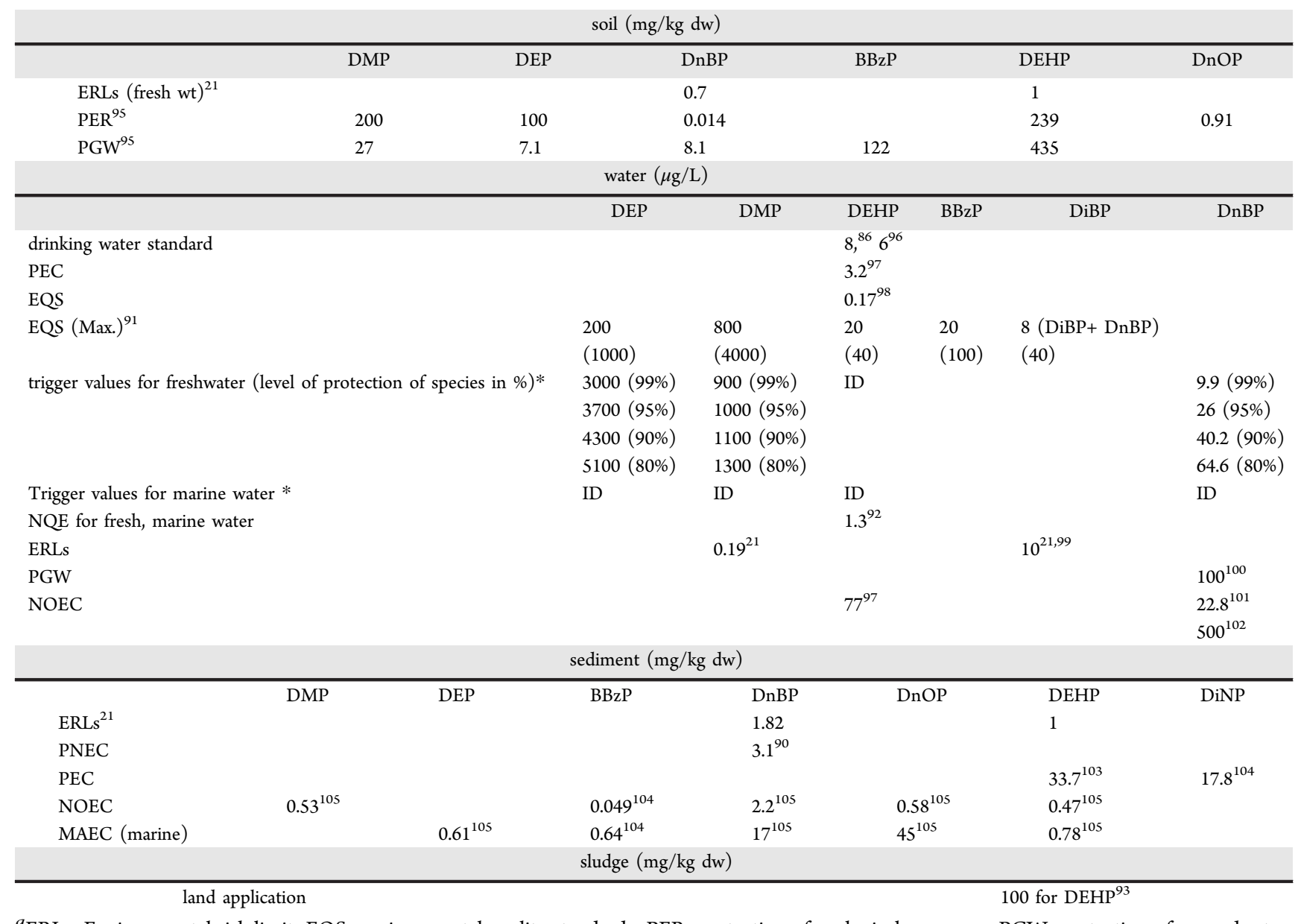

${ }^{a}$ ERLs: Environmental risk limit; EQS: environmental quality standards; PER: protection of ecological resources; PGW: protection of groundwater; PEC: predicted environmental concentration; NOEC: No observed effect concentration; MAEC: minor adverse effect concentration; ID: Insufficient data to derive a reliable trigger value. *Australian and New Zealand Guidelines for Fresh and Marine Water Quality. PAPER No. 4, Volume 1, The Guidelines (Chapters 1-7), October 2000.

Soil contaminated by PAEs also has a strong effect on the fauna and flora. ${ }^{60}$ Some PAEs (DEHP, DnBP, BBzP) and their metabolites are estrogenic and exhibit adverse reproductive effects. ${ }^{84}$ For rodents, PAEs can effect on testicular atrophy, liver damage, decreased fertility, decreased fetal weight, increased kidney weights and antiandrogenic activity. The LC50 of DEHP is estimated at $40 \mathrm{~g} / \mathrm{kg}$ and for DEP at $9.4 \mathrm{~g} /$ $\mathrm{kg}^{76,85}$ The effect of DEHP and its metabolites is notably important in young animals and prenatal exposure during pregnancy. DEHP also affects the female fertility. Oral exposure to DEHP in rodents induced fetal death and malformations. DEHP is categorized as Group-2B agent by International Agency for Research on Cancer (IARC) and cinfirmed to have 2.4 times higher risk causing female breast cancer. ${ }^{23}$

III.3. Regulations and Restrictions. Due to their potential health and environmental risks, PAEs have become a matter of worldwide concern. The WHO recommends the concentration of DEHP in drinking water below $8 \mu \mathrm{g} / \mathrm{L} .{ }^{86}$ U.S., Australia, Japan, and New Zealand have recommended a DEHP maximum value in drinking water to be $6 \mu \mathrm{g} / \mathrm{L}, 9,100$, and $10 \mu \mathrm{g} / \mathrm{L}$ respectively. ${ }^{87}$ Serious questions have been raised about toy and childcare applications, especially if the toys are susceptible to being chewed or sucked by children. ${ }^{88}$ The use of PAEs in toys or objects that can be placed in the mouth of children is now restricted or prohibited in many countries such as UE, U.S., Canada, Argentina, Brazil, and Japan. ${ }^{89,90}$

Due to the possible endocrine disrupting effects of PAEs, environmental quality standards (EQSs) based on the annual average concentrations in aquatic environments have been calculated, ${ }^{91}$ ranging from $20 \mu \mathrm{g} / \mathrm{L}$ for DEHP to $800 \mu \mathrm{g} / \mathrm{L}$ for DMP. However, EU proposed a guideline for environmental quality (NQE or Norme de qualité environnementale) of 1.3 $\mu \mathrm{g} / \mathrm{L}$ for DEHP in fresh and marine waters. ${ }^{92}$ While Australian and New Zealand guidelines proposed trigger values of 5100, 1300 , and $64.6 \mu \mathrm{g} / \mathrm{L}$ respectively for DMP, DEP, and BnBP as threshold values for the protections of $80 \%$ of species in freshwater (Table 2). However, for DEHP, there is insufficient data to derive a reliable trigger value neither in fresh and marine water (Table 2). The limit values established for DEHP in sludge for disposal onto farmland is proposed at $100 \mathrm{mg} / \mathrm{kg}$ $\mathrm{dw}^{93}$ while Danish Ministerial fixed the value at $50 \mathrm{mg} / \mathrm{kg}$ $\mathrm{dw} .{ }^{94}$ For natural sediment, Working Guidelines have been set for some PAEs (Table 2). The EU has included DnBP and DEHP in the list of substances suspected to cause endocrine disruption. ${ }^{13}$ DEHP has been classified by the EU as a substance causing toxic effects on fertility and development in humans. To minimize the health and environmental risk, DEHP has been replaced by DiNP and DiDP, which are 


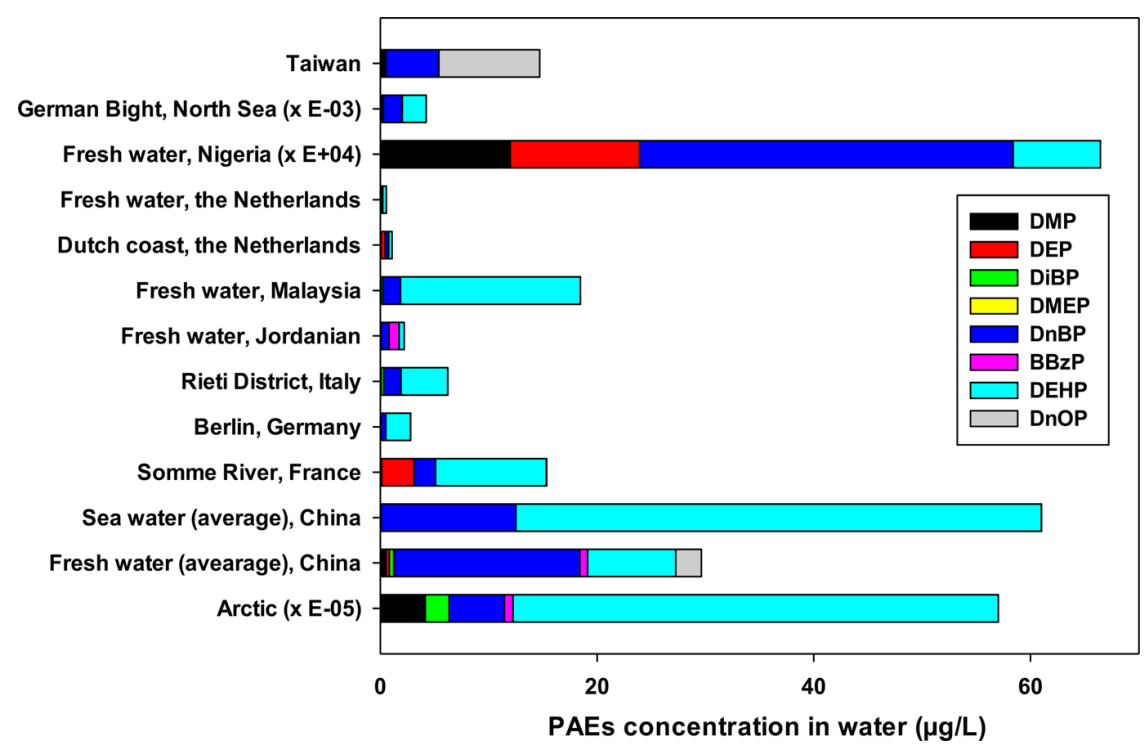

Figure 1. Composition of PAEs in different types of fresh and marine water for worldwide scale; detail values and references are given on Supporting Information Table $2 S$.

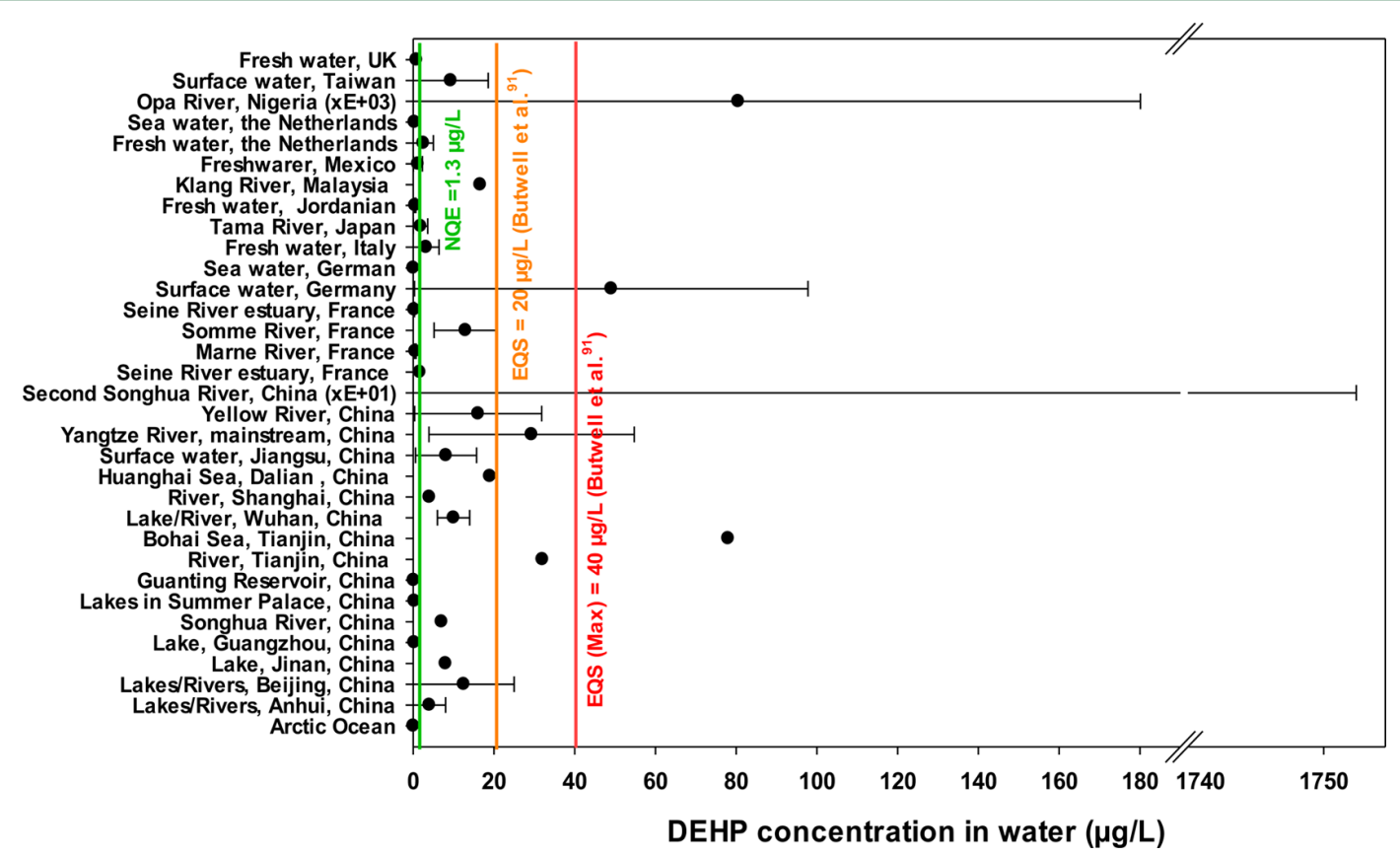

Figure 2. Worldwide contamination levels of DEHP in fresh and marine water compared to the NQE and EQS values (Detailed values and references are given in Supporting Information Table 2S).

considered not hazardous. Six PAEs (DMP, DEP, DnBP, BBzP, DEHP, and DnOP) have been included in the list of priority pollutants compiled by both the U.S. EPA and the EU and on the list of priority pollutants in Chinese waters. ${ }^{14}$ Table 2 presents different limited or recommended values available in different environmental matrices.

IV. Occurrence and Ecotoxicological State of PAEs. Even if PAEs can be eliminated from different environmental matrices via various processes as reported in previous sections, their extensive use and permanent emissions have resulted in their ubiquitous presence in the environment. PAEs have been widely detected in air, surface water, sediments, and soil on a worldwide scale. Indoor air is also highly contaminated by PAEs released from plastics and consumer products in homes, in suspended particulate matter and house dust. ${ }^{62,106}$ Concentration of PAEs in different environmental matrices has been reported in numerous papers and the compiled data are presented in Table $2 S$ in Supporting Information.

The ubiquity of PAEs in the environment today has given rise to a heightened awareness of the biochemical and toxicological roles of these compounds in the biosphere. As reported previously, some PAEs have been added to the priority list and limited or recommended values have been set for the most abundant and toxic PAEs. The main objectives are the protection of ecological resources and human health. For a better representation of contamination level and ecotoxicological status of the environment, the composition of PAEs in different matrices and their contamination levels as listed in SI 


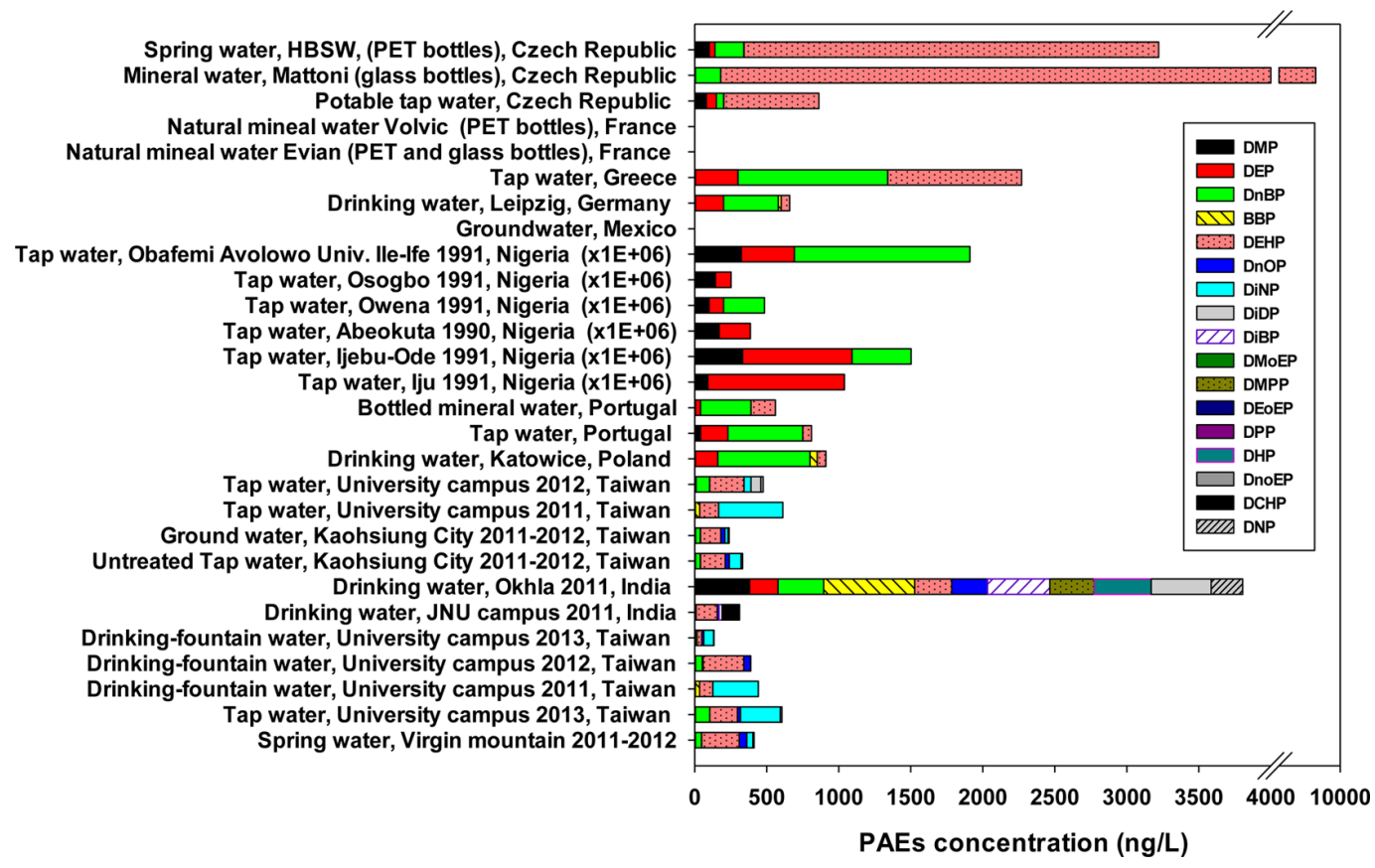

Figure 3. Composition of PAEs drinking water for worldwide scale; detailed values and references are given on Supporting Information Table $2 S$.

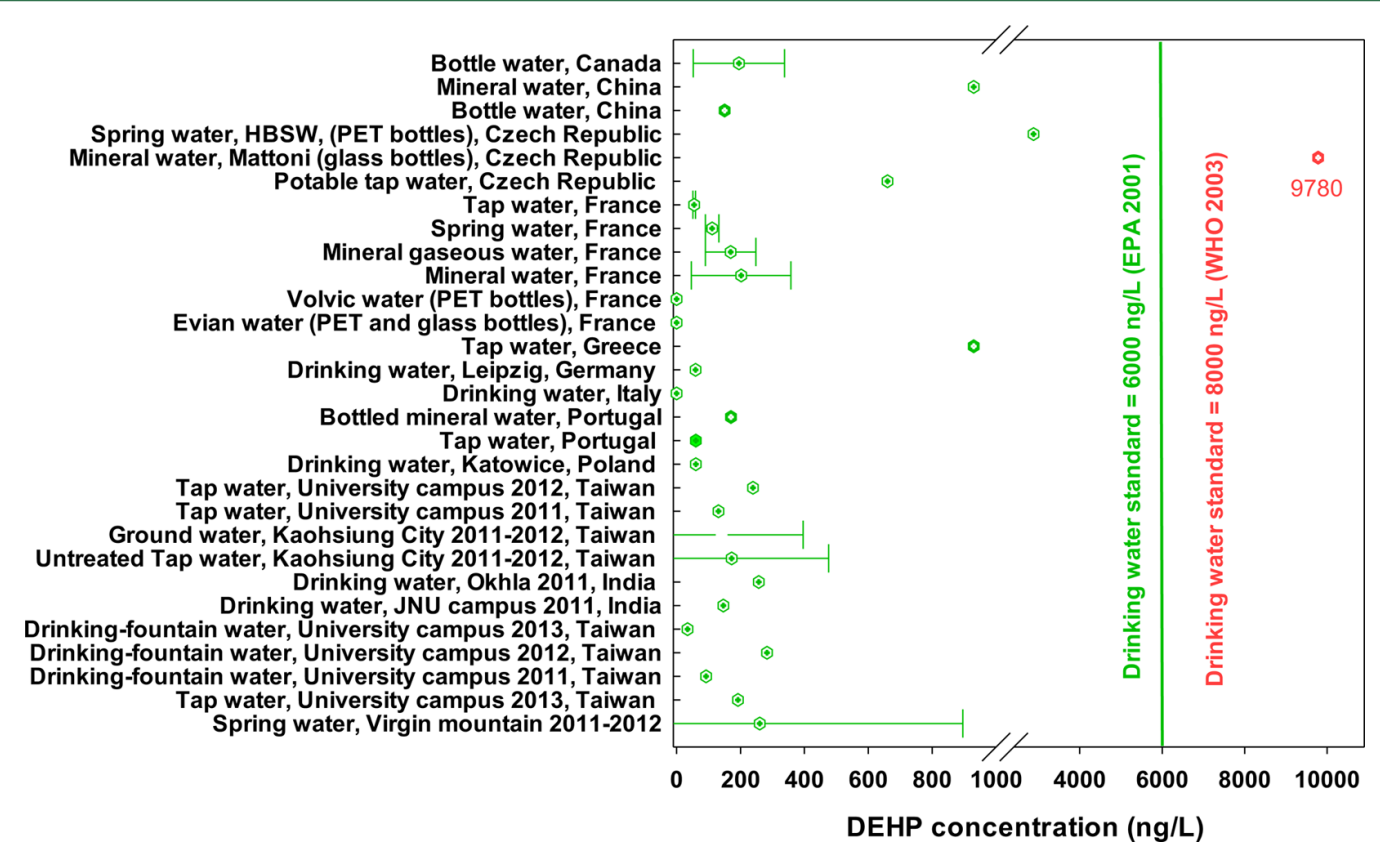

Figure 4. Worldwide contamination levels of DEHP in drinking water compared to the drinking water standard (Detailed values and references are given in Supporting Information Table 2S).

Table $2 S$ are presented in graph form and compared to the limits or recommended values.

IV.1. Fresh and Marine Surface Water. Numerous processes such as WWTP output, leaching, drainage, and atmospheric deposition are the major sources of PAEs in aquatic system. Among the large variety of PAEs, DMP, DEP, DiBP, DMEP, DnBP, BBP DEHP, and DnOP are among the most frequently detected in surface water (Supporting Information Table 2S). Figure 1 showed the composition of PAEs in fresh and marine water. Generally, studies focused on the six PAEs listed as priority substances which are the most toxic and also the predominant PAEs in the environment. Zheng et al. ${ }^{107}$ measured the concentration of 15 PAEs in water both in dissolved phase and associated with SSM. The $\sum_{6} \mathrm{PAEs}$ represents 64.8 and $66.9 \%$ of the $\sum_{15}$ PAEs respectively in dissolved phase and associated with SSM. DEHP and DnBP were predominant PAEs following by $\mathrm{DiBP}$ and BBzP. ${ }^{107}$ Figure 1 confirms the predominant of $\mathrm{DnBP}$ and DEHP in fresh and marine water.

Marine and coastal environment present low level of PAEs compared to freshwater (Supporting Information Table 2S, Figure 1). For better evaluation the ecotoxicological state of aquatic system based on PAEs, the data were compared with the guidelines or recommend values. Figure 2 showed the 


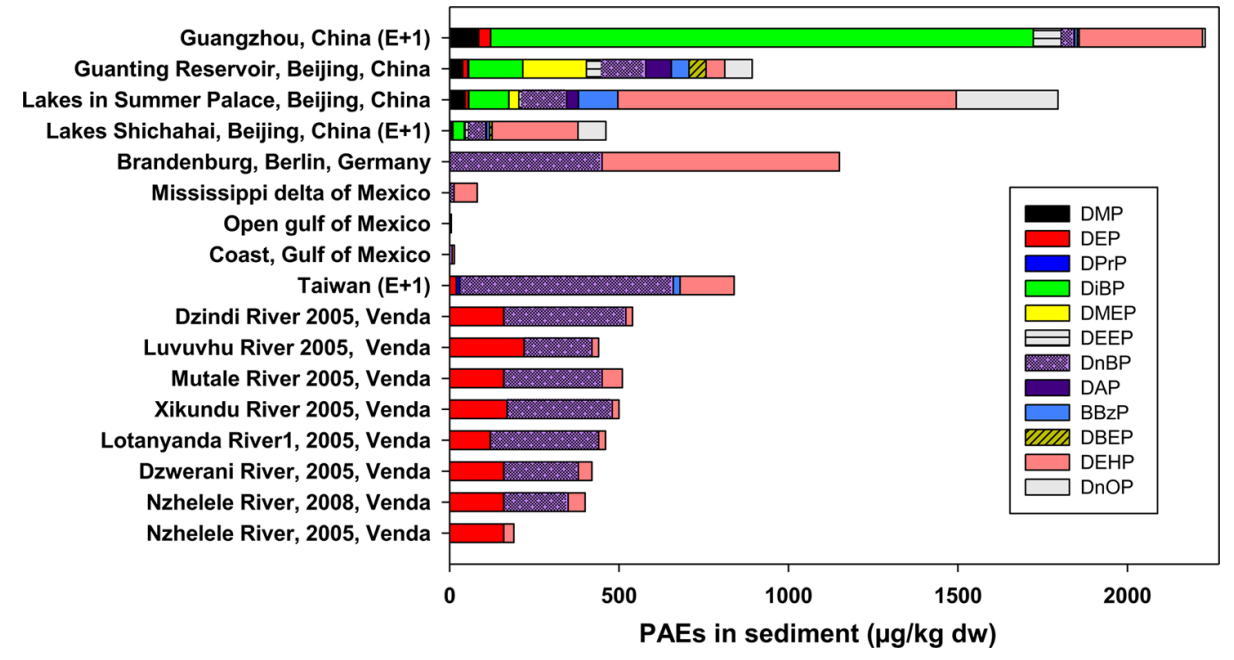

Figure 5. Worldwide composition of PAEs in sediment (Detailed values are given in Supporting Information Table 2S).

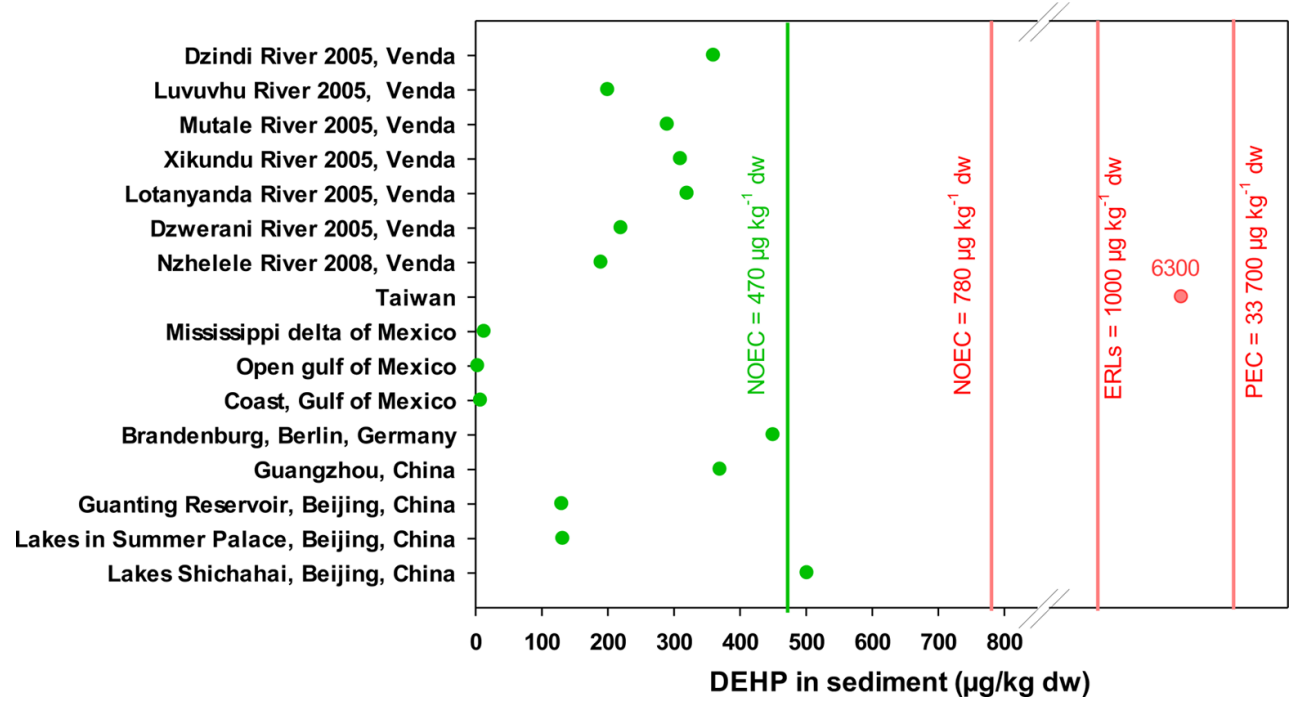

Figure 6. Contamination levels of DEHP in sediment compared to the NOEC, MAEC, ERLs, PEC and values (Detailed values and references are given on Supporting Informaiton Table 2S).

contamination level of DEHP in fresh and marine water for worldwide scale compared to NQE valued fixed by EU. Based on NQE $(1.3 \mu \mathrm{g} / \mathrm{L})$ in fresh and marine water, majority of measured point exceeded the guideline value. The value is much higher than the eqs $(0.17 \mu \mathrm{g} / \mathrm{L})^{98}$ and ERLs $(0.19 \mu \mathrm{g} /$ $\mathrm{L})^{21}$ (Figure 2). Some values were much higher than maximum allowance value of EQS reported by Butwell et al. ${ }^{91}$ at $40 \mu \mathrm{g} / \mathrm{L}$ for DEHP. It is difficult to evaluate the effects of PAEs on the aquatic environment because several parameters should be taken into consideration. Some values have been proposed by many research groups as reported previously. Predected effect concentration (PEC) which identifies the concentration above which harmful effects on organisms were expected to occur frequently has been proposed at $3.2 \mu \mathrm{g} / \mathrm{L} .{ }^{97}$ Above all, it is clear that the majority of concentrations shown in Figure 2 are considerably higher than all the limit values (PEC, NQE, ERLs) previously reported.

The contamination levels of DnBP, DMP, DEP and BBzP in fresh and marine water is presented in Supporting Information Figures $2 \mathrm{~S}$ to $4 \mathrm{~S}$. For DnBP, notably few samples are present at the level below the lowest observed effect concentration
(LOEC) and ERLs values set at 2 and $10 \mu \mathrm{g} / \mathrm{L}$, respectively. In some cases, the concentrations were higher than the PGW value fixed at $100 \mu \mathrm{g} / \mathrm{L}$ (Supporting Information Figure $2 \mathrm{~S}$ ). Thus, DnBP may affect not only aquatic organisms but also the groundwater resources. DMP and DEP were present under the EQS level except for the concentration reported by Fatoki and Ogunfowoka $^{108}$ from Nigeria (Supporting Information Table $2 \mathrm{~S}$; Figure $3 \mathrm{~S}$ ). Their concentrations were reported at very high levels, sometimes exceeding $500 \mathrm{mg} / \mathrm{L}$. The EQS of BBzP has been set at $20 \mu \mathrm{g} / \mathrm{L}$, with the maximum value set at $100 \mu \mathrm{g} / \mathrm{L}{ }^{91}$ Based on these EQS values, fresh and marine water possess acceptable levels for this compound. Only one value detected at Al-Khobar, Saudi Arabia was present at a high level $(36.48 \mu \mathrm{g} /$ $\mathrm{L})$ and exceeded the EQS.

IV.2. Drinking Water. PAEs present in drinking water can generally reach several $\mu \mathrm{g} / \mathrm{L}$, and in some cases, their levels can reach on the order of $\mathrm{mg} / \mathrm{L} .^{108}$ Figure 3 presents worldwide distribution of each PAE currently detected in drinking water. There is no predominant PAE notable among the large variety of PAEs detected in drinking water (i.e., mineral water, tap water, fountain water). Actually, it is difficult to determine the 


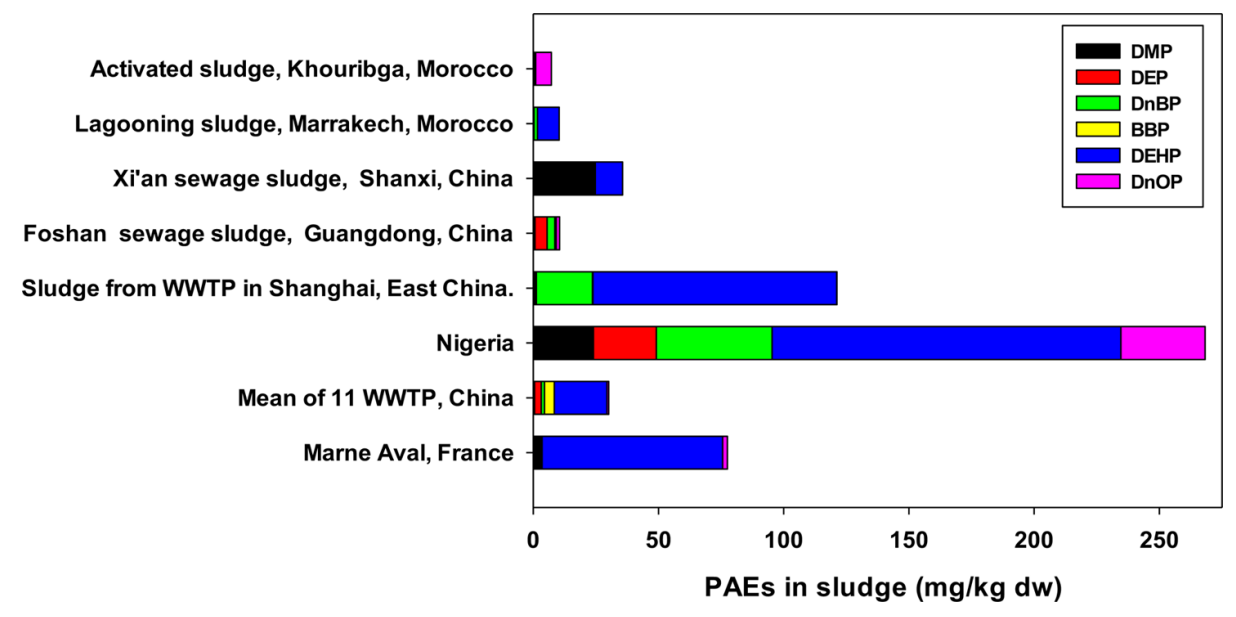

Figure 7. Composition of PAEs in sludge (Detailed values and references are given in Supporting Information Table 2S).

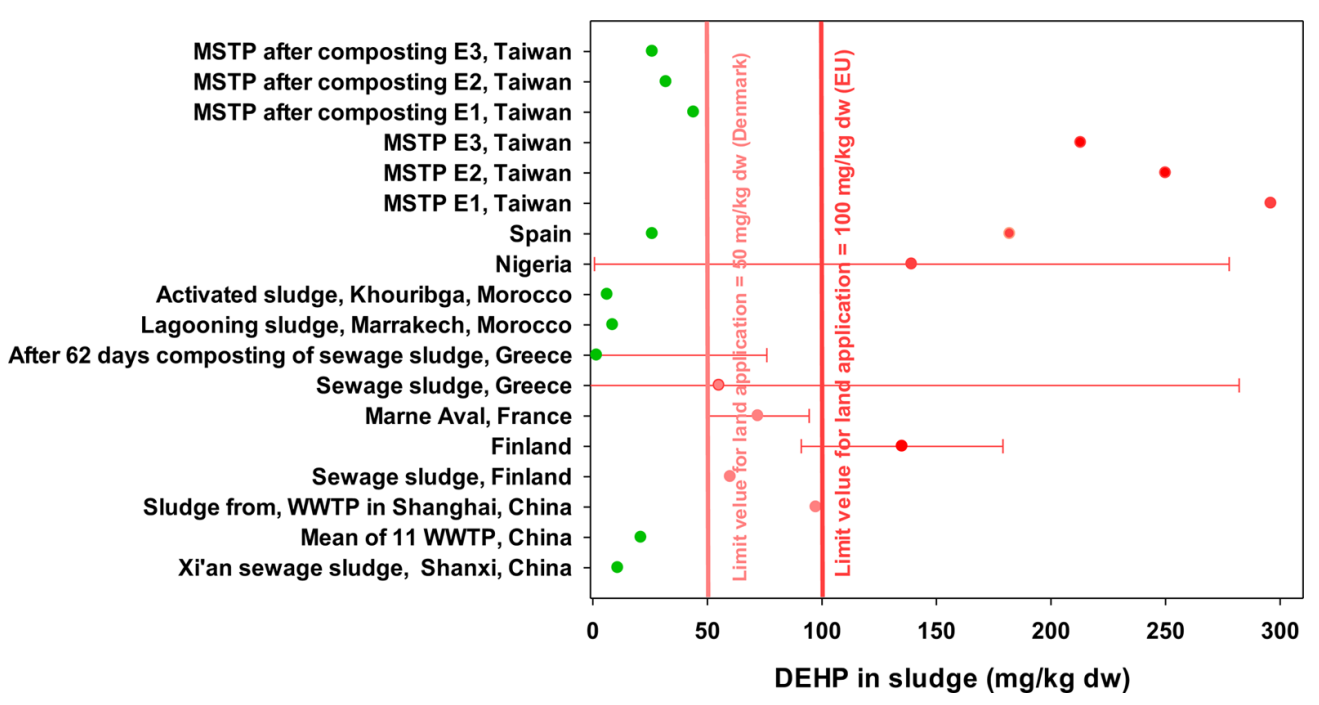

Figure 8. Worldwide contamination levels of DEHP in sludge compared to the limiting value (Detailed values and references are given in Supporting Information Table $2 \mathrm{~S}$ ).

predominant PAE because targeted compounds change from one study to another. Based in Figure 3, DMP, DEP, DnBP, and DEHP were the PAEs most often detected in drinking water. Nevertheless, even if six PAEs were added onto the priority list of the U.S. EPA, the drinking water standard for DEHP has been the only one established.

Figure 4 presents the contamination levels of drinking water by DEHP compared to the drinking water standards. The concentrations of DEHP most often detected in drinking water were in the range of a few hundred ng/L. Compared to the drinking water standard, the DEHP concentration does not exceed the guideline value, with the exception of mineral water (Mattoni) commercialized in the Czech Republic, where the concentration exceeded $9 \mu \mathrm{g} / \mathrm{L} .{ }^{109}$ Moreover, PAEs in drinking water can be removed by some novel technology such as the simultaneous electrocoagulation and electrofiltration process). ${ }^{66}$ This process coupled with the tubular carbon nanofiber/carbon/alumina com-posite membrane has been used to PAEs in drinking water with satisfactory revoval yield. The remove efficiencies ranged from 42 to $78 \%{ }^{66}$

IV.3. Sediment. In sediments, DnBP and DEHP were found in abundance (Supporting Information Table 2S; Figure 5). We note that $\mathrm{DnBP}$ can be used as a predictive indicator for the sediment $\sum_{16}$ PAEs concentration. ${ }^{110}$ DEHP concentrations have been compared to the ERLs, NOEC and PEC values. All measured levels are below the ERLs, NOEC, MAEC, and PEC values with the exception of the data reported for Lakes water from Beijing and Taiwan (Figure 6).

IV.4. Sludge. Presently, six PAEs were detected in wastewater, sewage sludge and compost samples. Their sum can exceed $250 \mathrm{mg} / \mathrm{kg}$ (Supporting Information Table 2S; Figure 7). In general, DEP, DnBP, and DEHP were the predominant PAEs in sludge and compost. However, composting can reduce the concentrations of PAEs initially present in sewage sludge, ${ }^{111,112}$ with removal rates of up to $77.3-100 \% .{ }^{112,113}$ Figure 7 shows the composition of PAEs in various types of sludge. In sludge, the removal rates of PAEs with short alkyl chains length were higher than those with long alkyl chains length. ${ }^{10,114}$ PAEs with short alkyl chains are more easily biodegraded and mineralized than those with long alkyl chains, of which some are considered resistant to degradation. However, during the composting, long alkyl chain length compounds could be transformed to compounds with shorter alkyl chain length compounds. ${ }^{60,114}$ Amir et al. ${ }^{114}$ has previously reported the transformation mechanism for the conversion of long alkyl chain length to DnBP, DEP, and DMP. 


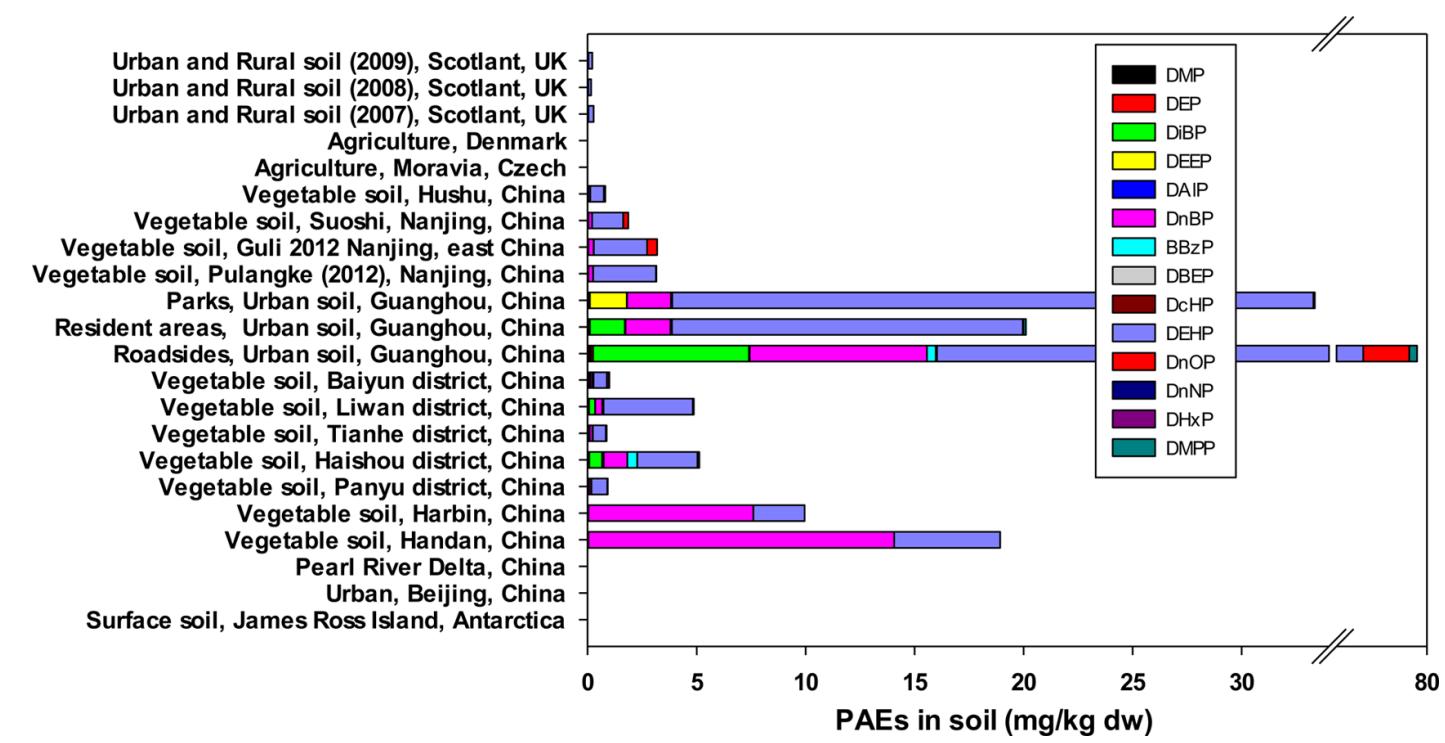

Figure 9. Worldwide composition of PAEs in soil (Detailed values and references are given in Supporting Information Table 2S).

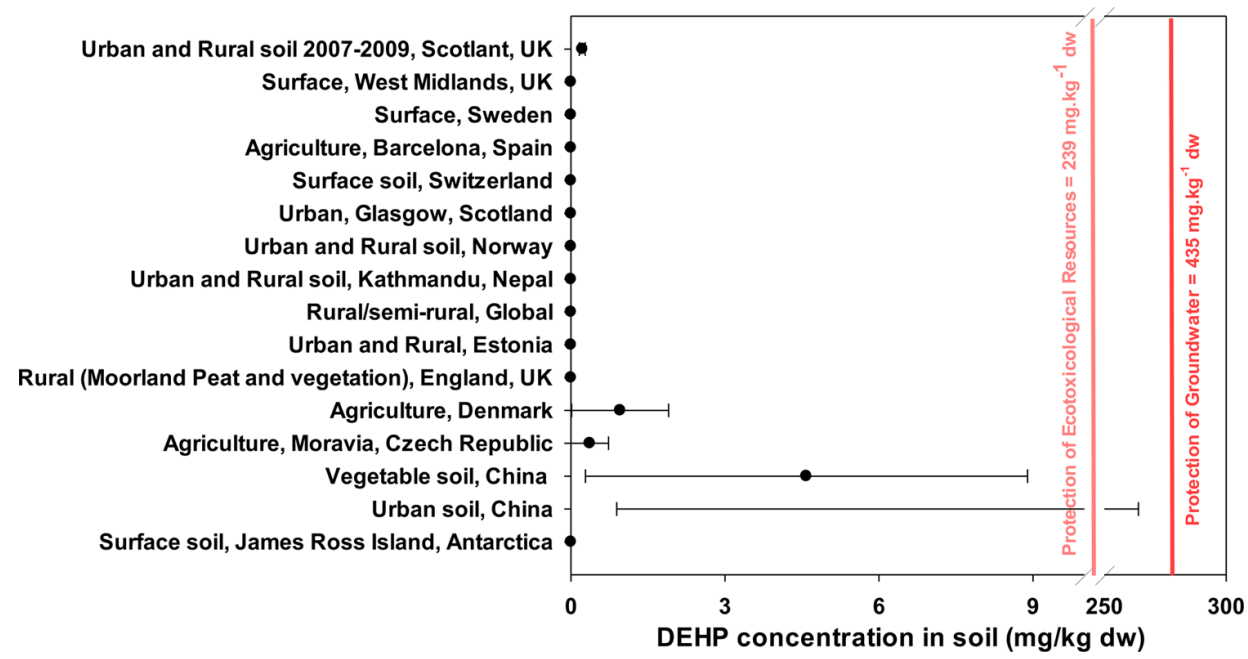

Figure 10. Worldwide contamination levels of DEHP in soil compared to the limiting values for PER and PGW (Detailed values and references are given in Supporting Information Table 2S).

The half-lives of DEHP were calculated at 45.4 days for lagooning sludge and 28.9 days for activated sludge. ${ }^{114}$ The degradation rates of the four PAEs were $\mathrm{DBP}>\mathrm{BBzP}>\mathrm{DEP}>$ DEHP. ${ }^{125}$ Generally, PAEs can be eliminated by WWTP with satisfactory removal yields from wastewater. ${ }^{7115-118}$ However, PAEs can accumulate in sludge which can be recycled for application on agricultural soil, which could then be a source of soil and water pollution by leaching or draining. Moreover, during a heavy rain period, WWTP can be overflown, thus leading to the contamination of the surrounding environment. Figure 8 shows the worldwide contamination levels of DEHP in sludge.

Most of different types of sludge contain high levels of DEHP that can exceed the limit value set by the EU and Danish Ministerial for land application (Figure 8). However, it is noteworthy that composting can be an effective approach to remove PAEs from sludge before land application because it reduces the PAEs initially present in sludge. ${ }^{111,112}$ Given the high half-life of PAEs in soil, stricter controls should be adopted before using sludge as a soil amendment. As reported in a previous section, the half-life of DEHP was estimated to be anywhere from 30 days $^{47}$ to a few hundred days. ${ }^{60}$

IV.5. Soil. Atmospheric deposition and sewage sludge used as a soil amendment are the major sources of PAEs in soil. Vikelsøe et al. ${ }^{118}$ have demonstrated the correlation between PAEs concentration in soils and the level of sludge amended. In soil, DnBP and DEHP were the most abundant PAEs (Figure 9). DnOP and DiBP were also frequently detected, but their concentrations were much lower than the concentrations of DnBP and DEHP. Generally, noncultivated soils contain the lowest contents of PAEs, suggesting that these types of pollutants are largely derived from human agricultural activities. To better evaluate the ecological risk, DEHP concentrations have been compared to Protection of Ecological Resources (PER) and PGW values (Figure 10). The concentration of DEHP is below the PGW level. In general, the DEHP concentrations in soil were below the levels of PER, with the exception of the urban soil measured at Guanghou in China (Figure 10). However, the DEHP concentrations often exceed the ERL values $(1 \mathrm{mg} / \mathrm{kg} \mathrm{wt}) .^{21}$ 


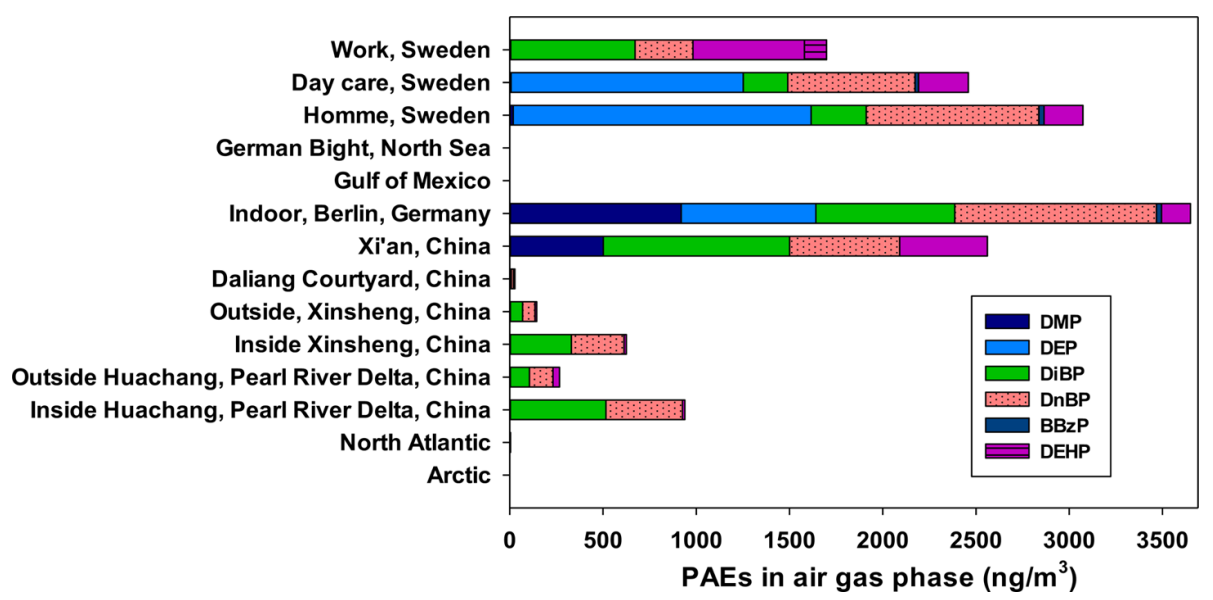

Figure 11. Worldwide contamination levels of PAEs in air (gas phase) (detailed values and references are given in Supporting Information Table 2S).

The contamination levels of DMP, DEP, DnBP, and DnOP are presented in Supporting Information Figures 5S and 6S. The DMP and DEP contamination levels were very low and did not exceed $0.4 \mathrm{mg} / \mathrm{kg} \mathrm{dw}$. Moreover, their values were much lower than the PGW and PER values set by the New York State Department of Environmental Conservation in 2010. The DnOP contamination was also detected at lower levels than the PER value set at $0.91 \mathrm{mg} / \mathrm{kg} \mathrm{dw}$. However, in a few cases DnBP was detected at levels higher than the PER and PGW values (Figure 12).

IV.6. Indoor and Outdoor Air. DnBP and DEHP were detected as the predominant PAEs in air. ${ }^{12,19,37,119,120}$ The total atmospheric levels of $\sum_{6}$ PAEs (DMP, DEP, DnBP, BBzP, DEHP, and DnOP) was $57.4 \mathrm{ng} / \mathrm{m}^{3}$ in Paris. ${ }^{37}$ As PAEs are released from anthropogenic activities, their concentrations are present at higher levels in a urban center than in suburban areas. $\sum_{6}$ PAEs were detected at $97 \mathrm{ng} / \mathrm{m}^{3}$ in the urban center versus $27.8 \mathrm{ng} / \mathrm{m}^{3}$ in the suburban areas. ${ }^{119}$ In the remote Arctic, the total concentration of atmospheric PAEs (i.e., $\sum_{6}$ PAEs) was detected at $2.14 \mathrm{ng} / \mathrm{m}^{3}$. Worldwide, $\sum_{6}$ PAEs were detected at higher levels in indoor air than outdoor air: $1014-1828 \mathrm{ng} / \mathrm{m}^{3}$ in China, ${ }^{62,65} 1289-2386 \mathrm{ng} / \mathrm{m}^{3}$ in Sweden, ${ }^{106} 545-2160 \mathrm{ng} / \mathrm{m}^{3}$ in the U.S. ${ }^{121,122}$

DMP, DEP, DiBP, DnBP, and DEHP were detected in marine aerosols. Their total concentrations were $0.79-12.4 \mathrm{ng} /$ $\mathrm{m}^{3}$, with an average of $2.6 \mathrm{ng} / \mathrm{m}^{3}$, which were higher than those reported in the North Sea to the high Arctic atmosphere $\left(0.38-1.02 \mathrm{ng} / \mathrm{m}^{3}\right)$ during the summer of $2004 .{ }^{39}$ A possible source of PAEs in the Arctic troposphere may be associated with long-range transport from midlatitudes and the subsequent deposition on the snow/ice sheet. The deposited PAEs onto snow and ice can also be released into the atmosphere with the increase of the ambient temperature during the spring and summer months. ${ }^{123}$ PAEs have been suggested to contribute to secondary oxidation products in organic aerosol fractions. ${ }^{124,125}$ Phthalic acid dominated the isomeric composition, which is consistent with those reported in continental aerosols. ${ }^{119}$ We note that a limiting value for this compound in ambient air has not been established.

Figures 11 and 12 show the composition of PAEs in air in both the gas phase and dust phase. In the gas phase, DiBP and $\mathrm{DnBP}$ were present in the highest frequency, which led to these compounds possessing the highest concentrations of the PAEs investigated. DEHP was also frequently detected in the gas

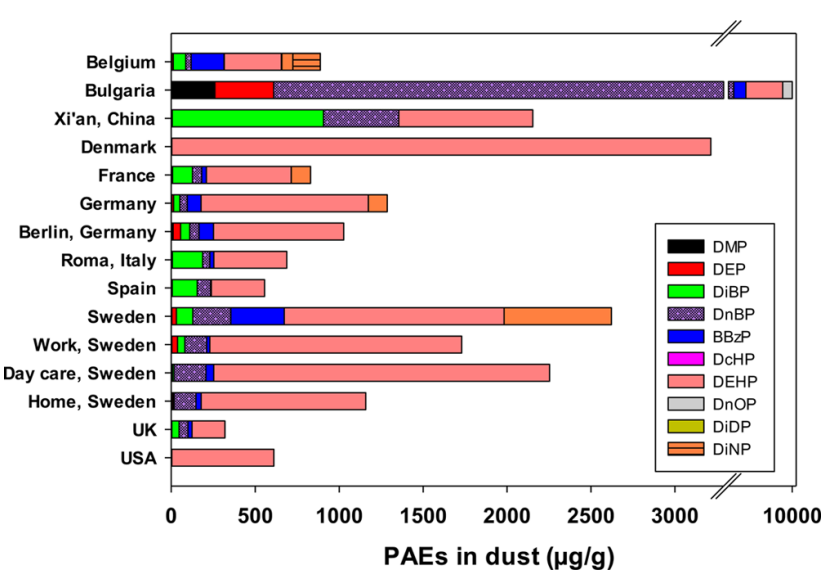

Figure 12. Worldwide contamination levels of PAEs in air (dust phase) (detailed values and references are given in Supporting Information Table 2S).

phase air, but its concentration was much lower than the concentrations detected for DiBP and DnBP (Figure 11). In the dust phase, DEHP was the predominant PAE identified, followed by DnBP and DiBP (Figure 12).

IV.7. PAEs in Wildlife. PAEs are hydrophobic compounds with $\log K_{\mathrm{OW}}$ can be up to 12.06 (Table 1 ) which indicate that they have strong ability to accumulate into organisms. Hydrophobicity of PAEs increase with increase of carbon leng chain. The contamination levels of some PAEs in biota including fishes, mammals, algae and others species are listed in Table $3 \mathrm{~S}$ in SI. Fishe species were reported to accumulate large variety of PAEs both parent and metabolite products including MPEs. PAEs and their metabolites were detected from the top of food chain (plankton, algae) to predator organisms (fish, marine mammals). ${ }^{10,126-131}$ Plankton and shellfish can accumulate individual PAE from not detected (nd) level to few hundreds ng/g. ${ }^{130,131}$ For freshwater ecosystem, the concentrations of individual PAE detected in fish species were in the range of nd to few hundreds $\mu \mathrm{g} / \mathrm{g} .^{127,128}$ Two order of magnetude lower were reported for marine fish ${ }^{127,129}$ (detailed values are given in Supporting Information Table 3S). In marine mammal, individual PAE was detected in the range of $<$ LOQ to few $\mu \mathrm{g} / \mathrm{g} .{ }^{130,131}$ The highest was detected in liver of Beluga whale Delphinapterus leucas which the 
concentration can be up to $4.15 \mu \mathrm{g} / \mathrm{g}$ of DEHP in wet weight animal. $^{130}$

Bioaccumulation/Bioconcentration factors (BAF or BCF) have been calculated for PAEs. A BCF or BAF $>1000$ indicates a high capacity for the species to accumulate or concentrate the pollutant. ${ }^{132}$ BAF and BCF of individual PAEs in wildlife are compiled in Supporting Information Table 5S. Few study was focused on BAF of PAEs in wilelife. The BAF of individual PAE (DEP, DnBP, BBzP, DEHP, and DnOP) in three mammals and five invertebrates $<0.25$ exepted for $\mathrm{DnOP}$ in inverterbrates that can be up to 2400 (Supporting Information Table 5S). ${ }^{133}$ Fishs have been reported to concentrate PAEs at significant level with total BCF of 57, 117, 45-663, 11-900, 207, and $2668-2125 \mathrm{~mL} / \mathrm{g} /$ wet respectively for DMP, DEP, BBzP, DEHP, DiOP, and DnDP. Staples et al. ${ }^{10}$ have compiled litherature data on the total BCF for aquatic organisms. They reported that crustacea and insect can accumulate DnBP with total BCF of $185-1485$ and $458-714 \mathrm{~mL} / \mathrm{g} /$ wet, respectively. Total BCF of $100 \mathrm{~mL} / \mathrm{g} /$ wet has been reported for BBzP for Mollusca. ${ }^{10}$ Total BCF of DHxP has been reported to be 999$5269 \mathrm{~mL} / \mathrm{g} /$ wet for crustacea. DnOP can bioconcentrate various aquatic species including in algae, mollusca, crustacean and insecta with total BCF of 8412, 699, 1429, and $1338 \mathrm{~mL} /$ g/wet, respectively. ${ }^{10}$ Similarly, DEHP were measured at high level of total BCF at 987, 264-2627, 83-3916, and 315-1892 $\mathrm{mL} / \mathrm{g} /$ wet respectively for algae, mollusca, crustacean and insect. $^{10}$ Total BCF of DiNP in mollusca was reported at 1844 $\mathrm{mL} / \mathrm{g} /$ wet. Total BCF of DiDP were measured at 2998-3977 and $90-147 \mathrm{~mL} / \mathrm{g} /$ wet for mollusca and crustacean. ${ }^{10} \mathrm{DnBP}$, DnOP, and DEHP were the three PAEs that can be bioconcentrated at high level in fish, shellfish and green algae (Supporting Information Table 5S). Low molecular weigh PAEs (DMP and DEP) were detected to accumiulate at low level in aquatic species. The low values of BAF and BCF for some PAEs may be due to the fact that PAEs can be degraded or metabolized be species. Indedd, microbes from diverse habitats have been showed to degrade PAEs. ${ }^{10}$ High metabolite product of DEHP (MEHP) has been detected in plankton ${ }^{130}$ which indicate that plankton can biodegrade DEHP by converting to MEHP. Thus, BCF can be an important factor of PAEs fate in the environment because it leads to biodegradation. Primary biodegradation half-lives of PAEs range from $<1$ day to $\sim 2$ weeks and clear trends between differents PAEs or between fresh water and marine waters are not apparent. ${ }^{10}$ Ultimate degradation half-lives of DEHP (averaged about 12-67 days depend on temperature) are about an order of magnitude higher compared to primary biodegradation half-lives.

\section{CONCLUSIONS}

PAEs can be degraded by different biotic and abiotic pathways, as such they are not expected to be highly persistent in aquatic and terrestrial environments (air, water, sediment, and soil). Global half-lives of PAEs in air vary from few hours to few days. PAEs in water can be eliminated by hydrolysis, photolysis, photooxidation, and biodegradation. However, there is a paucity of data dealing with accurate description of degradation processes for the complete set of PAEs. Current knowledge shows that degradation half-lives of individual PAE ranges from a few days to months in soils and sediments according to the environmental conditions. Biodegradation activity appears to be greater than abiotic degradation in surface waters, sediments and soils. PAEs with low molecular weight are more easily biodegraded than those with higher molecular weights. In natural environments, large variations of degradation of PAEs are caused by their physicochemical properties, the type of bacterial strains, temperature variations and nutritional conditions. Primary degradation half-life in water is expected to be on the order of less than 1 week, whereas the half-lives in soils can be up to several months. Longer half-lives are more likely under anaerobic conditions and in cold, nutrient poor environments.

PAEs can be eliminated from different environmental matrices via various processes. However, their extensive use and permanent emissions have resulted in their ubiquitous presence in the environment. These products can cause toxic effects on fertility and the development of humans as well as on many aquatic and terrestrial species. Consequently, the chronic exposure of PAEs to aquatic organisms and humans raises many questions. This study contributes in establishing the biogeochemical cycle of PAEs in the environment according to anthropogenic, hydrological and climatic factors.

\section{ASSOCIATED CONTENT}

S Supporting Information

Additional information as noted in the text. This material is available free of charge via the Internet at http://pubs.acs.org.

\section{AUTHOR INFORMATION}

\section{Corresponding Author}

*Phone: +33(0)3-28-77-85-24; fax: +33(0)3-20-43-48-22; email: sopheak.net@univ-lille1.fr.

\section{Notes}

The authors declare no competing financial interest.

\section{ACKNOWLEDGMENTS}

We are grateful for the financial support provided by the MERMEX/MISTRALS project and Labex OT-Med. We thank the associate editor and the anonymous reviewers for improving the quality of the manuscript. We acknowledge the financial support from the PACA region, which provided a $\mathrm{PhD}$ scholarship for A. Paluselli.

\section{REFERENCES}

(1) Kimber, I.; Dearman, R. J. An assessment of the ability of phthalates to influence immune and allergic responses. Toxicology 2010, 271 (3), 73-82.

(2) Simoneit, B. R. T.; Medeiros, P. M.; Didyk, B. M. Combustion products of plastics as indicators for refuse burning in the atmosphere. Environ. Sci. Technol. 2005, 39, 6961-6970.

(3) Serôdio, P.; Nogueira, J. M. F. Considerations on ultra-trace analysis of phthalates in drinking water. Water Res. 2006, 40 (13), 2572-2582.

(4) Cadogan, D. F.; Papez, M.; Poppф, A. C.; Scheubel, J. An assessment of the release, occurrence and possible effect of plasticizers in the environment. Prog. Rubber Plast. Technol. 1993, 10 (1), 1-19.

(5) Xie, Z.; Ebinghaus, R.; Temme, C.; Lohmann, R.; Cara, A.; Ruck, W. Occurrence and air-sea exchange of phthalates in the Arctic. Environ. Sci. Technol. 2007, 41 (13), 4555-4560.

(6) Fu, P.; Kawamura, K.; Barrie, L. A. Photochemical and other sources of organic compounds in the Canadian high Arctic aerosol pollution during winter-spring. Environ. Sci. Technol. 2009, 43, 286292.

(7) Dargnat, C.; Teil, M. J.; Chevreuil, M.; Blanchard, M. Phthalate removal throughout wastewater treatment plant: case study of Marne Aval station (France). Review. Sci. Total Environ. 2009, 407 (4), 12351244. 
(8) Net, S.; Dumoulin, D.; El-Osmani, R.; Rabodonirina, S.; Ouddane, B. Case study of PAHs, Me-PAHs, PCBs, phthalates and pesticides contamination in the Somme River water, France. Int. J. Environ. Res. 2014, 8 (4), 1159-1170.

(9) Gao, D.; Li, Z.; Wen, Z.; Ren, N. Occurrence and fate of phthalate esters in full-scale domestic wastewater treatment plants and their impact on receiving waters along the Songhua River in China. Chemosphere 2014, 95, 24-32.

(10) Staples, C. A.; Peterson, D. R.; Parkerton, T. F.; Adams, W. J. The environmental fate of phthalates esters: A literature review. Chemosphere 1997, 35, 667-749.

(11) Barreca, S.; Indelicato, R.; Orecchio, S.; Pace, A. Photodegradation of selected phthalates on mural painting surfaces under UV light irradiation. Microchemical J. 2014, 114, 192-196.

(12) Wang, X.; Tao, W.; Xu, Y.; Feng, J.; Wang, F. Indoor phthalate concentration and exposure in residential and office buildings in Xi'an, China. Atmos. Environ. 2014, 87, 146-152.

(13) Commission Staff Working Document on the Implementation of the Community Strategy for Endocrine Disrupters-A Range of Substances Suspected of Interfering with the Hormone Systems of Humans and Wildlife; CEC (Commission of the European Communities): Brussels, 2007

(14) Yuan, B.; Li, X.; Graham, N. Aqueous oxidation of dimethyl phthalate in a $\mathrm{Fe}(\mathrm{VI}) / \mathrm{TiO}_{2} / \mathrm{UV}$ reaction system. Water Res. 2008, 42, $1413-1420$

(15) Chen, C. Y. Biosynthesis of di-(2-ethylhexyl) phthalate (DEHP) and di- $n$-butyl phthalate (DBP) from red alga-Bangia atropurpurea. Water Res. 2004, 38 (4), 1014-1018.

(16) Schiedek, T. Impact of plasticizers (phthalic acid esters) on soil and groundwater quality. Groundwater Qual.: Rem. Protect. 1995, 225, 149-156.

(17) Mackintosh, C. E.; Maldonado, J. A.; Ikonomou, M. G.; Gobas, F. A. P. C. Sorption of phthalate esters and PCBs in a marine ecosystem. Environ. Sci. Technol. 2006, 40 (11), 3481-3488.

(18) Schreiber, A.; Fu, F.; Yang, O.; Wan, E.; Gu, E.; Le Blanc, Y. Increasing and Confuidence in Detection When Analyzing Phthalates by LC-MS/MS, AB Sciex, AN 3690411-01, 2011.

(19) Peijnenburg, W. J. G. M.; Struijs, J. Occurrence of phthalate esters in the environment of the Netherlands. Ecotoxicol. Environ. Saf. 2006, 63, 204-215.

(20) Earls, A. O.; Axford, I. P.; Braybrook, J. H. Gas chromatographymass spectrometry determination of the migration of phthalate plasticisers from polyvinyl chloride toys and childcare articles. $J$. Chromatogr. A 2003, 983 (1-2), 237-246.

(21) Van Wezel, A. P.; Van Vlaardingen, P.; Posthumus, R.; Crommentuijn, G. H.; Sijm, D. T. H. M. Environmental risk limits for two phthalates, with special emphasis on endocrine disruptive properties. Ecotoxicol. Environ. Saf. 2000, 46, 305-321.

(22) Koniecki, D.; Wang, R.; Moody, R. P.; Zhu, J. Phthalates in cosmetic and personal care products: concentrations and possible dermal exposure. Environ. Res. 2011, 111 (3), 329-336.

(23) IARC. Monographs on the Evaluation of Carcinogenic Risks to Humans. Some Industrial Chemicals; International Agency for Research on Cancer: Lyon, France, 2000, p. 77.

(24) Staples, C. A.; Adams, W. J.; Parkerton, T. F.; Gorsuch, W. Aquatic toxicity of eighteen phthalate esters. Environ. Toxicol. Chem. 1997b, 16, 875-891.

(25) Cousins, I.; Mackay, D. Correlating the physical-chemical properties of phthalate esters using the 'three solubility' approach. Chemosphere 2000, 41 (9), 1389-1399.

(26) Lyman, W. J.; Reehl, W. F.; Rosenblatt, D. H. Handbook of Chemical Property Estimation Methods-Environmental Behavior of Organic Compounds; American Chemical Society: Washington, DC, 1990; Vol. 960.

(27) Okamoto, Y.; Hayashi, T.; Toda, C.; Ueda, K.; Hashizume, K.; Itoh, K.; Nishikawa, J.; Nishihara, T.; Kojima, N. Formation of estrogenic products from environmental phthalate esters under light exposure. Chemosphere 2006, 64 (10), 1785-1792.
(28) Abdel-Daiem, M. M.; Rivera-Utrilla, J.; Ocampo-Pérez, R.; Méndez-Díaz, J. D.; Sánchez-Polo, M. Environmental impact of phthalic acid esters and their removal from water and sediment by different technologies-A review. J. Environ. Manage. 2012, 109, 164178 .

(29) Net, S.; Delmont, A.; Sempéré, R.; Paluselli, A.; Ouddane, B. Reliable quantification of phthalates in environmental matrices (air, water, sediment, sludge and soil): A review. Sci. Total. Environ. 2015, $515-516,162-180$

(30) Brasche, S.; Bischof, W. Daily time spent indoors in German homes-Baseline data for the assessment of indoor exposure of German occupants. Int. J. Hyg Environ. Health 2005, 208 (4), 247253.

(31) Hwang, H. M.; Park, E. K.; Young, T. M.; Hammock, B. D. Occurrence of endocrine-disrupting chemicals in indoor dust. Sci. Total Environ. 2008, 404 (1), 26-35.

(32) Cizdziel, J. V.; Hodge, V. F. Attics as archives for house infiltrating pollutants: trace elements and pesticides in attic dust and soil from southern Nevada and Utah. Microchem. J. 2000, 64 (1), 8592.

(33) HSDB, 1994. Hazardous Substances Data Bank. Bethesda, MD, National Library of Medicine, National Toxicology Information Program, 11 September 1994.

(34) Behnke, W.; Nolting, F.; Zetzsch, C. An aerosol smog chamber for testing abiotic degradation. In Pesticide Science and Biotechnology, Proceedings of the International Congress of Pesticide Chemistry; Greenhalgh, R., Roberts, T.R. Eds. ; Blackwell Publishers: Oxford, UK, 1987; pp 401-404.

(35) Orecchio, S.; Indelicato, R.; Barreca, S. Determination of selected phthalates by gas chromatography-mass spectrometry in mural paintings from Palermo (Italy). Microchem. J. 2014, 114, 187191.

(36) Maertens, R. M.; Bailey, J.; White, P. A. The mutagenic hazards of settled house dust: a review. Mutat. Res. 2004, 567 (2-3), 401-425.

(37) Teil, M- J.; Blanchard, M.; Chevreuil, M. Atmospheric fate of phthalate esters in an urban area (Paris-France). Sci. Total Environ. 2006, 354, 212-223.

(38) Zeng, F.; Lin, Y.; Cui, K.; Wen, J.; Ma, Y.; Chen, H.; Zhu, F.; Ma, Z.; Zeng, Z. Atmospheric deposition of phthalate esters in a subtropical city. Atmos. Environ. 2010, 44 (6), 834-840.

(39) Xie, Z.; Ebinghaus, R.; Temme, C.; Caba, A.; Ruck, W. Atmospheric concentrations and air-sea exchanges of phthalates in the North Sea (German Bight). Atmos. Environ. 2005, 39, 3209-3219.

(40) Xu, G.; Li, F. S.; Wang, Q. H. Occurrence and degradation characteristics of dibutyl phthalate (DBP) and di-(2-ethylhexyl) phthalate (DEHP) in typical agricultural soils of China. Sci. Total Environ. 2008, 393 (2), 333-340.

(41) Zeng, F.; Cui, K. Y.; Xie, Z. Y.; Wu, L. N.; Luo, D. L.; Chen, L. X.; Lin, Y. J.; Liu, M.; Sun, G. X. Distribution of phthalate esters in urban soils of subtropical city, Guangzhou, China. J. Hazard. Mater. 2009, 164 (2), 1171-1178.

(42) Wang, W. X.; Zhang, Y. L.; Wang, S. L.; Fan, C. Q.; Xu, H. Distributions of phthalic esters carried by total suspended particulates in Nanjing, China. Environ. Monit. Assess. 2012, 184 (11), 6789-6798.

(43) Wolfe, N. L.; Steen, W. C.; Bums, L. A. Phthalate ester hydrolysis: Linear free energy relationships. Chemosphere 1980, 9 (78), 403-408.

(44) Tedetti, M.; Kawamura, K.; Narukawa, M.; Joux, F.; Charrière, B.; Sempéré, R. Hydroxyl radical-induced photochemical formation of dicarboxylic acids from unsaturated fatty acid (oleic acid) in aqueous solution. J. Photochem. Photobiol. A Chem. 2007, 188, 135-139.

(45) Vione, D.; Minella, M.; Maurino, V.; Minero, C. Indirect photochemistry in sunlit surface waters: Photoinduced production of reactive transient species. Chem.-Eur. J. 2014, 20, 10590-10606.

(46) Wolfe, N. L.; Burns, L. A.; Steen, W. C. Use of linear free energy relationship and an evaluative model to assess the fate and transport of phthalate esters in the aquatic environment. Chemosphere 1980, 9, 393-402. 
(47) Cousins, I. T.; Palm, A. Physical-chemical properties and estimated environmental fate of brominated and iodinated organic compounds. In The Handbook of Environmental Chemistry. 3R; Neilson, A. H., Ed.; Springer-Verlag: Berlin/Heidelberg, 2003; pp 301-334.

(48) Camanzo, J.; Rice, C. P.; Jude, D. J.; Rossmann, R. Organic priority pollutants in nearshore fish from 14 Lake Michigan tributaries and embayments, 1983. J. Great Lakes Res. 1987, 13 (3), 296-309.

(49) DeVault, D. S. Contaminants in fish from Great Lakes harbors and tributary mouths. Arch. Environ. Contam. Toxicol. 1985, 14, 587594.

(50) U.S. EPA. Health and Environmental Effects Profile for Phthalic Acid Esters; US Environmental Protection Agency, Office of Research and Development, Environmental Criteria and Assessment Office (EPA/600/22): Cincinnati, OH, 1989.

(51) Wofford, H. W.; Wilsey, C. D.; Neff, G. S.; Giam, C. S.; Neff, J. M. Bioaccumulation and metabolism of phthalate esters by oysters, brown shrimp and sheephead minnows. Ecotoxicol. Environ. Saf. 1981, $5,202-210$.

(52) Barrows, M. E.; Petrocelli, S. R.; Macek, K. J.; Carroll, J. J. Bioconcentration and elimination of selected water pollutants by bluegill sunfish (Lepomis macrochirus). In Dynamics, Exposure and Hazard Assessment of Toxic Chemicals; Haque R., Ed.; Ann Arbor. Science: Ann Arbor, MI, 1980; pp 379-392.

(53) Veith, G. D.; Macek, K. J.; Petrocelli, S. R.; Carroll, J. An Evaluation of Using Partition Coefficients and Water Solubility to Estimate Bioconcentration Factors for Organic Chemicals in Fish, Aquatic Toxicology. In Eaton, J. G., Parrish, P. R., Hendricks, A. C., Eds.; American Society for Testing and Materials: Philadelphia, PA 1980; pp 116-129 (ASTM Special Technical Publication 707),

(54) Yuan, S.-Y.; Huang, I.-C.; Chang, B.-V. Biodegradation of dibutyl phthalate and di-(2-ethylhexyl) phthalate and microbial community changes in mangrove sediment. J. Hazard. Mater. 2010, $184,826-831$.

(55) Yuan, S. Y.; Liu, C.; Liao, C. S.; Chang, B. V. Occurrence and microbial degradation of phthalate esters in Taiwan river sediments. Chemosphere 2002, 49, 1295-1299.

(56) Chang, B. V.; Liao, C. S.; Yuan, S. Y. Anaerobic degradation of diethyl phthalate, di-n-butylphthalate, and di-(2-ethylhexyl) phthalate from river sediment in Taiwan. Chemosphere 2005, 58 (11), 16011607.

(57) Fish, T. D. ; Jones, J. R. ; Johnson, T. Characteristics of various hydrosoils and their relative importance in the biodegradation of DEHP. In 77th Annual Meeting Abstracts Am. Soc. Microbiol: New Orleans, 1977.

(58) Tegatz, M. E.; Plaia, G. R.; Deans, C. H. Toxicity of dibutyl phthalate-contaminated sediment of laboratory-and field-colonized estuarine benthic communities. Bull. Environ. Contain. Toxicol. 1986, $37,141-150$.

(59) Otton, S. V.; Sura, S.; Blair, J.; Ikonomou, M. G.; Gobas, F. A. P. C. Biodegradation of mono-alkyl phthalate esters in natural sediments. Chemosphere 2008, 71 (11), 2011-2016.

(60) Cartwright, C. D.; Thompson, I. P.; Burns, R. G. Degradation and impact of phthalate plasticizers on soil microbial communities. Environ. Toxicol. Chem. 2000, 19 (5), 1253-1261.

(61) Heudorf, U.; Mersch-Sundermann, V.; Angerer, J. Phthalates: Toxicology and exposure. Int. J. Hyg. Environ. Health 2007, 210 (5), 623-634.

(62) Guo, Y.; Kannan, K. Comparative assessment of human exposure to phthalate esters from house dust in China and the United States. Environ. Sci. Technol. 2011, 45 (8), 3788-3794.

(63) Weschler, C. J. Indoor/outdoor connections exemplified by processes that depend on an organic compound's saturation vapour pressure. Atmos. Environ. 2003, 37, 5455-5465.

(64) Das, M. T.; Ghosh, P.; Thakur, I. S. Intake estimates of phthalate esters for South Delhi population based on exposure media assessment. Environ. Pollut. 2014, 189, 118-125.

(65) Zhang, L.; Wang, F.; Ji, Y.; Jiao, J.; Zou, D.; Liu, L.; Shan, C.; Bai, Z.; Sun, Z. Phthalate esters (PAEs) in indoor $\mathrm{PM}_{10} / \mathrm{PM}_{2.5}$ and human exposure to PAEs via inhalation of indoor air in Tianjin, China. Atmos. Environ. 2014, 85, 139-146.

(66) Yang, G. C. C.; Yen, C- H.; Wang, C. L. Monitoring and removal of residual phthalate esters and pharmaceuticals in the drinking water of Kaohsiung City, Taiwan. J. Hazard. Mater. 2014, 277, 53-61.

(67) Cousins, A. P.; Holmgren, T.; Remberger, M. Emissions of two phthalate esters and BDE 209 to indoor air and their impact on urban air quality. Sci. Total Environ. 2014, 470-471, 527-535.

(68) Clark, K. E.; David, R. M.; Guinn, R.; Kramarz, K. W.; Lampi, M. A.; Staples, C. A. Modeling human exposure to phthalate esters: A comparison of indirect and biomonitoring estimation methods. Hum. Ecol. Risk Assess. 2011, 17 (4), 923-965.

(69) Liou, S.-H.; Yang, G. C. C.; Wang, C.-L.; Chiu, Y.-H. Monitoring of PAEMs and beta-agonists in urine for a small group ofexperimental subjects and PAEs and beta-agonists in drinking waterconsumed by the same subjects. J. Hazard. Mater. 2014, 277, $169-179$.

(70) Chen, J. A.; Liu, H.; Qiu, Z.; Shu, W. Analysis of di-n-butyl phthalate and other organic pollutants in Chongqing women undergoing parturition. Environ. Pollut. 2008, 156 (3), 849-853.

(71) Main, K. M.; Mortensen, G. K.; Kaleva, M. M.; Boisen, K. A.; Damgaard, I. N.; Chellakooty, M.; Schmidt, I. M.; Suomi, A- M.; Virtanen, H. E.; Petersen, J. H.; Andersson, A- M.; Toppari, J.; Skakkebæk, N. E. Human breast milk contamination with phthalates and alterations of endogenous reproductive hormones in infants three months of age. Environ. Health Perspect 2006, 114 (2), 270-276.

(72) Singh, S.; Li, S. S.-L. Epigenetic effects of environmental chemicals bisphenol A and phthalates. Int. J. Mol. Sci. 2012, 13, 10143-10153.

(73) Kolena, B.; Petrovicova, I.; Pilka, T.; Pucherova, Z.; Munk, M.; Matula, B.; Vankova, V.; Petlus, P.; Jenisova, Z.; Rozova, Z.; Wimmerova, S.; Trnovec, T. Phthalate exposure and health-related outcomes in specific types of work environment. Int. J. Environ. Res. Public Health 2014, 11 (6), 5628-5639.

(74) Oie, L.; Hersoug, L. G.; Madsen, J. O. Residential exposure to plasticizers and its possible role in the pathogenesis of asthma. Environ. Health Perspect. 1997, 105 (9), 972-978.

(75) Blanc, P. D.; Toren, K. How much adult asthma can be attributed to occupational factors? Am. J. Med. 1999, 107 (6), 580587.

(76) Benson, R. Hazard to the developing male reproductive system from cumulative exposure to phthalate esters-dibutyl phthalate, diisobutyl phthalate, butylbenzyl phthalate, diethylhexyl phthalate, dipentyl phthalate, and diisononyl phthalate. Regul. Toxicol. Pharmacol. 2009, 53 (2), 90-101.

(77) Sims, J. N.; Graham, B.; Pacurari, M.; Leggett, S. S.; Tchounwou, P. B. Ndebele, K. Di-ethylhexylphthalate (DEHP) modulates cell invasion, migration and anchorage independent growth through targeting S100P in LN-229 glioblastoma cells. Int. J. Environ. Res. Public Health 2014, 11, 5006-5019.

(78) Howdeshell, K. L.; Rider, C. V.; Wilson, V. S.; Gray, L. E., Jr. Mechanisms of action of phthalate esters, individually and in combination, to induce abnormal reproductive development in male laboratory rats. Environ. Res. 2008, 108 (2), 168-176.

(79) Vethaak, A. D.; Rijs, G. B. J.; Schrap, S. M.; Ruiter, H.; Gerritsen, A.; Lahr, J. Oestrogens and Xeno-Estrogens in the Aquatic Environment of the Netherlands, Occurrence, potency and biological effectsRIZA/RIKS-report no. 2002-001, 2002.

(80) Harris, C. A.; Henttu, P.; Parker, M. G.; Sumpter, J. P. The estrogenic potential of phthalate esters in vitro. Environ. Health Perspect. 1997, 105 (8), 802-811.

(81) Ye, T.; Kang, M.; Huang, Q.; Fang, C.; Chen, Y.; Shen, H.; Dong, S. Exposure to DEHP and MEHP from hatching to adulthood causesreproductive dysfunction and endocrine disruption in marine medaka (Oryzias melastigma). Aquat. Toxicol. 2014, 146, 115-126.

(82) Chen, X.; Xu, S.; Tan, T.; Lee, S. T.; Cheng, S. H.; Lee, F. W. F.; Xu, S. J. L.; Ho, K. C. Toxicity and estrogenic endocrine disrupting 
activity of phthalates and their mixtures. Int. J. Environ. Res. Public Health 2014, 11 (3), 3156-3168.

(83) Oehlmann, J.; Schulte-Oehlmann, U.; Kloas, W.; Jagnytsch, O.; Lutz, I.; Kusk, K. O.; Wollenberger, L.; Santos, E. M.; Paull, G. C.; Van Look, K. J. W.; Tyler, C. R. A critical analysis of the biological impacts of plasticizers on wildlife. Philos. Trans. R. Soc., B 2009, 364 (1526), 2047-2062.

(84) Scholz, N. Ecotoxicity and biodegradation of phthalate monoesters. Chemosphere 2003, 53 (8), 921-926.

(85) AESN (Agence de l'Eau Seine Normandie). Guide Pratique Des Substances Toxiques Dans les Eaux Douces et Littorales du Bassin SeineNormandie, 2008.

(86) Guidelines for Drinking Water Quality, 3rd ed.; WHO (World Health Organization): Geneva, 2004; Vol. 1.

(87) Maycock, D.; Fawell, J.; Merrington, G.; Watts, C. Review of England and Wales monitoring data for which a national or international standard has been set. Guidel. Drinking Water Qual. 2008, 1-148.

(88) Marcilla, A.; García, S.; García-Quesada, J. C. Study of the migration of PVC plasticizers. J. Anal. Appl. Pyrolysis 2004, 71 (2), $457-463$.

(89) Chimical Inspection and Regulation Service (CIRS). http:// www.cirs-reach.com/Testing/Phthalates_Testing.html.

(90) Bette, H. California bans phthalates in toys for children. Chemical and Engineering News, 12. 2007. http://pubs.acs.org/cen/ news/85/i43/8543news4.html.

(91) Butwell, A. J.; Hetheridge, M.; James, H. A.; Johnson, A. C.; Young, W. F. Endocrine Disrupting Chemicals in Wastewater-A Review of Occurrence and Removal, Report No. 02/TX/04/5; Water Industry Research Limited (UKWIR): London, 2001.

(92) Journal officiel de l'Union européenne. Directive 2013/39/UE du parlement Européen et du Conseil du 12 août 2013.

(93) CEC (Commission of the European Communities), 2000. Working document on sludge 3rd draft Report No.ENV.E.3/LM. DG. Environment, Brussels. Retrieved 31 July 2003 from The European Water Association. http://www.ewaonline.de/pages/sludge en.pdf.

(94) Danish Ministerial Order. No. 823, 1996. Application of Waste Products for Agricultural Purposes, September 16, 1996.

(95) New York State Department of Environmental Conservation, 2010. SoilCleanup Guidance. http://www.dec.ny.gov/docs/ remediation_hudson_pdf/cpsoil.pdf.

(96) U.S. EPA. Methods for organic chemical analysis of municipal and industrial wastewater, Method 606: Phthalate esters. Code Fed. Regul. 40. 2001.

(97) Naito, W.; Gamo, Y.; Yoshida, K. Screening-level risk assessment of di(2-ethylhexyl)phthalate for aquatic organisms using monitoring data in Japan. Environ. Monit. Assess. 2006, 115, 451-471.

(98) Marchand, M.; Tissier, C.; Tixier, C.; Tronczynski, J. Les contaminants chimiques dans le Directive Cadre sur l'Eau. Septembre 2004-R.INT.DIR/DEL-PC/2004.11， 2004. http://www.ifremer.fr/ envlit/documentation/documents.htm.

(99) EU. European Union Risk Assessment Report for Dibutyl Phthalate with Addendum to the Environmental Section 2004; Office for Official Publications of the European Communities: Luxembourg, 2004.

(100) Ward, T. J.; Boerie, R. L. Early Life Stage Toxicity of Di-nButylphthalate (DnBP) to the Rainbow Trout (Oncorhynchus mykiss) under Flow-through Conditions; Resource Analysts, Inc., Environ. Systems Division: Hampton, NH, 1991; unpublished.

(101) Ohtani, H.; Miura, I.; Ichikawa, Y. Effects of dibutyl phthalate as an environmental endocrine disrupter on gonadal sex differentiation of genetic males of the frog Rana rugosa. Environ. Health Perspect. 2000, 108 (12), 1189-1193.

(102) Lee, S. K.; Veeramachaneni, D. N. R. Subchronic exposure to low concentrations of di-n-butyl phthalate disrupts spermatogenesis in Xenopus laevis frogs. Toxicol. Sci. 2005, 84 (2), 394-407.

(103) EU. European Union Risk Assessment Report for Bis(2Ethylhexyl) Phthalate. Draft of March 2006; Office for Official Publications of the European Communities: Luxembourg, 2006.
(104) Barrick, R., Becker, S.; Brown, L.; Beller, H.; Pastorok, R. Sediment Quality Values Refinement: 1988 Update and Evaluation of Puget Sound AET, Vol. 1 Prepared for the Puget Sound Estuary Program. PTI Environmental Services: Bellevue, Washington, 1988; (Cited from: D. D. MacDonald, S. L Smith, M. P. Wong and P. Murdoch. 1992. The development of Canadian Marine Environmental Quality Guidelines. Marine).

(105) Sediment Management Standards; Washington State Department of Ecology, April 1991.

(106) Bergh, C.; Torgrip, R.; Emenius, G.; Ostman, C. Organophosphate and phthalate esters in air and settled dust-A multilocation indoor study. Indoor Air 2011, 21 (1), 67-76.

(107) Zheng, X.; Zhang, B- T.; Teng, Y. Distribution of phthalate acid esters in lakes of Beijing and its relationship with anthropogenic activities. Sci. Total Environ. 2014, 476-77, 107-113.

(108) Fatoki, O. S.; Ogunfowokan, A. O. Determination of phthalate ester plasticizers in the aquatic environment of southwestern Nigeria. Environ. Int. 1993, 19, 619-623.

(109) Prokůpková, G.; Holadová, K.; Poustka, J.; Hajšlová, J. Development of a solid-phase microextraction method for the determination of phthalic acid esters in water. Anal. Chim. Acta 2002, 457 (2), 211-223.

(110) Zeng, F.; Cui, K.; Xie, Z.; Liu, M.; Li, Y.; Lin, Y.; Zeng, Z.; Li, F. Occurrence of phthalate esters in water and sediment of urban lakes in a subtropical city, Guangzhou, South China. Environ. Int. 2008, 34, 372-380.

(111) Pakou, C.; Kornaros, M.; Stamatelatou, K.; Lyberatos, G. On the fate of LAS, NPEOs and DEHP in municipal sewage sludge during composting. Bioresour. Technol. 2009, 100, 1634-1642.

(112) Cai, Q. Y.; Mo, C. H.; Lu, H.; Zeng, Q. Y.; Wu, Q. T.; Li, Y. W. Effect of composting on the removal of semivolatile organic chemicals (SVOCs) from sewage sludge. Bioresour. Technol. 2012, 126, 453-457.

(113) Cheng, H- F.; Kumar, M.; Lin, J- G. Degradation kinetics of di(2-ethylhexyl) phthalate (DEHP) and organic matter of sewage sludge during composting. J. Hazard. Mater. 2008, 154, 55-62.

(114) Amir, S.; Hafidi, M.; Merlina, G.; Hamdi, H.; Jouraiphy, A.; El Gharous, M.; Revel, J. C. Fate of phthalic acid esters during composting of both lagooning and activated sludges. Process. Biochem. 2005, 40 (6), 2183-2190.

(115) Marttinen, S.; Kettunen, R.; Sormunen, K. M.; Rintala, J. Removal of bis(2-ethylhexyl) phthalate at a sewage treatment plant. Water Res. 2003, 37 (6), 1385-1393.

(116) Marttinen, S. K.; Kettunen, R. H.; Rintala, J. A. Occurrence and removal of organic pollutants in sewages and landfill leachates. Sci. Total Environ. 2003, 301 (1-3), 1-12.

(117) Tran, B. C.; Teil, M. J.; Blanchard, M.; Alliot, F.; Chevreuil, M. BPA and phthalate fate in a sewage network and an elementary river of France. Influence of hydroclimatic conditions. Chemosphere 2015, 119, $43-51$.

(118) Vikelsǿe, J.; Thomsen, M.; Carlsen, L. Phthalates and nonylphenols in profiles of differently dressed soils. Sci. Total Environ. 2002, 296, 105-116.

(119) Wang, Z.; Jing, M.; Lee, F. S.; Wang, X. Synthesis of 8hydroxyquinoline Bonded Silica (SHQ) and its application in flow injection-inductively coupled plasma mass spectrometry analysis of trace metals in seawater. Chin. J. Anal. Chem. 2006, 34 (4), 459-462.

(120) Wang, P.; Wang, S. L.; Fan, C. Q. Atmospheric distribution of particulate- and gas-phase phthalic ester (PAEs) in a Metropolitan City, Nanjing, East China. Chemosphere 2008, 72 (10), 1567-1572.

(121) Adibi, J. J.; Whyatt, R. M.; Williams, P. L.; Calafat, A. M.; Camann, D.; Herrick, R.; Nelson, H.; Bhat, H. K.; Perera, F. P.; Silva, M. J.; Hauser, R. Characterization of phthalate exposure among pregnant women assessed by repeat air and urine samples. Environ. Health Perspect. 2008, 116 (4), 467-473.

(122) Rudel, R. A.; Dodson, R. E.; Perovich, L. J.; Morello-Frosch, R.; Camann, D. E.; Zuniga, M. M.; Yau, A. Y.; Just, A. C.; Brody, J. G. Semivolatile endocrine-disrupting compounds in paired indoor and outdoor air in two Northern California communities. Environ. Sci. Technol. 2010, 44 (17), 6583-6590. 
(123) Fu, P. Q.; Kawamura, K.; Chen, J.; Charrière, B.; Sempéré, R. Organic molecular composition of marine aerosols over the Arctic Ocean in summer: Contributions of primary emission and secondary aerosol formation. Biogeosciences 2013, 10, 653-667.

(124) Kawamura, K.; Yasui, O. Diurnal changes in the distribution of dicarboxylic acids, ketocarboxylic acids and dicarbonyls in the urban Tokyo atmosphere. Atmos. Environ. 2005, 39, 1945-1960.

(125) Kundu, S.; Kawamura, K.; Andreae, T. W.; Hoffer, A.; Andreae, M. O. Molecular distributions of dicarboxylic acids, ketocarboxylic acids and dicarbonyls in biomass burning aerosols: Implications for photochemical production and degradation in smoke layers. Atmos. Chem. Phys. 2010, 10, 2209-2225.

(126) Brown, D.; Thompson, R. S. Phthalates and the aquatic environment: Part II The bioconcentration and depuration of di-2ethylhexyl phthalate (DEHP) and di-isodecyl phthalate (DIDP) in mussels (Mytilus edulis). Chemosphere 1982, 11, 427-435.

(127) Cheng, Z.; Nie, X. P.; Wang, H. S.; Wong, M. H. Risk assessments of human exposure to bioaccessible phthalate esters through market fish consumption. Environ. Int. 2013, 54-58, 75-80.

(128) Huang, P. C.; Tien, C. J.; Sun, Y. M.; Hsieh, C. Y.; Lee, C. C. Occurrence of phthalates in sediment and biota: Relationship to aquatic factors and the biota-sediment accumulation factor. Chemosphere 2008, 73, 539-544.

(129) Güven, K. C.; Coban, B. Phthalate pollution in fish Sarda sarda, Engraulis encrasicolus, Mullus surmuletus, Merlangius merlangus and shrimp Parapenaeus longirostris. J. Black Sea/Mediterr. Environ. 2013, 19 (2), 185-189.

(130) Morin, A. Distribution of phthalate esters in a marine mammal food chain from Canada's Eastern Arctic, 2003.

(131) Fossi, M. C.; Panti, C.; Guerranti, C.; Coppola, D.; Giannetti, M.; Marsili, L.; Minutoli, R. Are baleen whales exposed to the threat of microplastics? A case of study of the Mediterranean fin whale (Balaenoptera physalus). Mar. Pollut. Bull. 2012, 64, 2374-2379.

(132) Porter, A.; Hayden, N. Nonylphenol in the Environment: A Critical Review; Department of Civil and Environmental Engineering, University of Vermont: Burlington, VT, 2002.

(133) HAZWRAP. Loring Air Force Base Ecological Risk Methodology; Martin Marietta Energy Systems, 1994. 